\title{
Gut dysbiosis protects against liver injury in autophagy deficient mice by FXR-FGF15 feedback signaling
}

\author{
Shengmin Yan ${ }^{1,2}$, Bilon Khambu ${ }^{1,2}$, Xiaoyun Chen ${ }^{1}$, Zheng Dong ${ }^{3,4}$, Grace Guo ${ }^{5}$, Xiao-Ming Yin ${ }^{1,2 *}$ \\ ${ }^{1}$ Department of Pathology and Laboratory Medicine, Indiana University School of Medicine, \\ Indianapolis, IN 46202, USA \\ ${ }^{2}$ Department of Pathology and Laboratory Medicine, Tulane University School of Medicine, New \\ Orleans, LA 70112, USA \\ ${ }^{3}$ Department of Cell Biology and Anatomy, Medical College of Georgia at Augusta University, Augusta, \\ GA 30912, USA \\ ${ }^{4}$ Charlie Norwood VA Medical Center, Augusta, GA 30904, USA \\ ${ }^{5}$ Department of Pharmacology and Toxicology, Rutgers University, Piscataway, NJ 08854, USA.
}

\section{*. Address correspondence to:}

Xiao-Ming Yin, MD, PhD

Department of Pathology and Laboratory Medicine,

Tulane University School of Medicine,

New Orleans, LA 70112

504-988-1170 (phone)

504-988-7389 (fax)

xmyin@tulane.edu (e-mail) 


\section{ABSTRACT}

Objective: The gut microbiota (GM) can have complicated and often undetermined interactions with the function of many organs in the body. GM is altered in a variety of liver diseases, but the significance of such changes on the liver disease is still unclear. Hepatic autophagy deficiency causes

liver injury accompanied with cholestasis. Here, we investigated the impact of such hepatic changes on GM and in turn the effect of gut dysbiosis on liver injury.

Design: Fecal microbiota from mice with liver-specific loss of autophagy-related gene 5 (Atg5), Atg $5^{\text {Ahep }}$ mice, were analyzed by $16 \mathrm{~S}$ sequencing. Antibiotics (ABX) was used to modulate GM in mice. Cholestyramine was used to reduce the enterohepatic bile acid (BA) level. The functional role of fibroblast growth factor 15 (FGF15) and ileal farnesoid X receptor (FXR) was examined in mice overexpressing FGF15 gene, or given a fibroblast growth factor receptor 4 (FGFR4) inhibitor.

Results: The composition of GM was significantly changed with a notable increase of BA-metabolizing bacteria in $A \operatorname{tg} 5^{\Delta \text { hep }}$ mice, leading to a lower proportion of tauro-conjugated BAs and a higher proportion of unconjugated BAs in the intestine, which markedly activated ileal FXR with an increased expression of FGF15. ABX or cholestyramine treatment exacerbated liver injury and ductular reaction, and decreased FGF15 expression, whereas modulating FGF15 signaling altered liver phenotypes in the autophagy-deficient mice.

Conclusion: Gut dysbiosis can remedy liver injury in Atg5 $5^{\text {hep }}$ mice through the FXR-FGF15 signaling. Antibiotics use in the condition of liver injury may have unexpected adverse consequences via the gutliver axis.

Keywords: Gut dysbiosis, Liver injury, Adaptive response, FGF15, Autophagy 


\section{SHORT SUMMARY}

\section{What is already known about this subject?}

- Gut microbiota (GM) can be altered during hepatic pathogenesis.

- $\quad \mathrm{GM}$ are involved in bile acid (BA) metabolism.

- Autophagy deficiency in the liver disrupts BA homeostasis and causes cholestatic injury.

\section{What are the new findings?}

- Deficiency of autophagy in the liver causes alteration of GM, which leads to a higher proportion of BA-metabolizing bacteria.

- GM contribute to the activation of ileal farnesoid X receptor (FXR) and a higher expression of fibroblast growth factor 15 (FGF15) in autophagy deficient condition in the liver, which is associated with decreased levels of conjugated BAs and increased levels of unconjugated BAs in the intestine.

- Manipulations that lead to GM alteration, intestinal BA signaling, or FGF15 signaling can all modulate the liver phenotype.

- $\quad$ BA and GM together can act as a sensor to liver injury to trigger FGF15-mediated protective mechanism.

\section{How might it impact on clinical practice in the foreseeable future?}

- These findings indicate that gut dysbiosis in the scenario of liver disease can be beneficial, suggesting cautions should be exercised in the use of antibiotics during specific liver diseases.

- If antibiotics need to be used in patients with liver diseases it may be beneficial to enhance the FXR-FGF15 feedback signaling to retain the protective effect of GM. 


\section{INTRODUCTION}

Gut microbiota (GM) consist of a diverse community of symbiotic bacteria and have a complex interplay with the host [1]. Interactions between GM and the host result in production of metabolites by microbes, including secondary bile acids (BAs) [1]. Alteration of GM has been associated with multiple diseases, including fatty liver disease. Gut dysbiosis is found in patients with nonalcoholic fatty liver disease (NAFLD) and steatohepatitis (NASH) [2]. In patients with alcohol-related liver disease, the microbiota composition and function are varied in association with the severity of liver condition and whether the patients are active drinkers [3]. On the other hand, gut dysbiosis may contribute to hepatic pathogenesis by translocation of microbial-associated molecular patterns (MAMPs) and live bacteria that can across the gut barrier [4]. However, evidence of beneficial impacts with clear mechanisms is still scarce.

BAs are produced in hepatocytes through two major biosynthetic pathways, including the classic

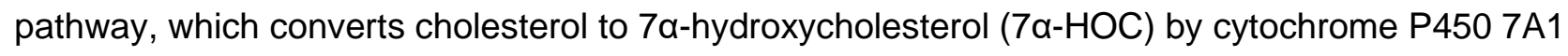
(CYP7A1), and the alternative pathway, which converts cholesterol to 27-hydroxycholesterol (27-HOC) by cytochrome P450 27A1 (CYP27A1) [5, 6]. Eventually, the classic pathway leads to the synthesis of cholic acid (CA) and chenodeoxycholic acid (CDCA), whereas the alternative pathway only leads to the synthesis of CDCA in mice $[5,6]$. In the human liver, CDCA is an end product, however, CDCA is further converted to muricholic acids (MCAs) by cytochrome P450 2C70 (CYP2C70) in the mouse liver $[5,6]$. Primary BAs are conjugated following synthesis and secreted to the intestine, where they are converted by GM into secondary BAs and reabsorbed by the liver through the portal circulation $[5,6]$. Dysfunction of BA metabolism and gut dysbiosis can be associated with each other, often in the context of liver diseases $[4,6]$. Gut dysbiosis has been found in patients with primary biliary cholangitis or primary sclerosing cholangitis, and in a mouse model of cholestasis [4, 7]. It is not known whether gut dysbiosis would in turn affect liver pathogenesis in the context of dysregulated BA metabolism. 
Macroautophagy, hereafter simply referred to as autophagy, is an evolutionarily conserved degradation process and is critical for hepatic homeostasis [8]. Deficiency of key autophagy-related genes (Atg) in the liver, e.g. Atg5 and Atg7, causes severe liver injury, fibrosis, and tumorigenesis [9, 10]. Our previous study demonstrates autophagy deficiency-induced liver injury is accompanied with altered BA metabolism, cholestatic injury and impaired hepatic farnesoid X receptor (FXR) activity [11]. We thus hypothesized that autophagy deficiency in the liver could alter GM, which could have further effects on the hepatic phenotype.

Our study shows indeed that hepatic autophagy deficiency leads to an increased proportion of BAmetabolizing bacteria and the alteration of BA composition in the intestine. The significance of these changes is the enhanced activation of ileal FXR and an increased expression of fibroblast growth factor 15 (FGF15). Unexpectedly, we found an exacerbated liver injury and ductular reaction in autophagydeficient livers following GM removal or blockage of the FGF15- fibroblast growth factor receptor 4 (FGFR4) signaling pathway. Our findings thus indicate that gut dysbiosis can be beneficial, not just being harmful as shown in other studies, in protecting the liver from further injury, and the mechanism is medicated by a gut-liver signaling axis. In addition, the findings imply that antibiotics use in the condition of liver injury should be cautious, considering the potential adverse effect on the liver via the gut-liver signaling. 


\section{METHODS}

Atg5 $5^{\mathrm{F} / \mathrm{F}}$ mice (B6.129S-Atg5tm1Myok) [10] and Atg $7^{\mathrm{F} / \mathrm{F}}$ mice [12] had been reported in previous studies. $A \operatorname{tg} 5^{\Delta \text { hep }}$ and $A \operatorname{tg} 7^{\Delta \text { hep }}$ mice were created by crossing $A \operatorname{tg} 5^{\mathrm{F} / \mathrm{F}}$ or $A \operatorname{tg}{ }^{\not / F}$ with the Alb:Cre transgenic mice (The Jackson Laboratory, Bar Harbor, ME), respectively. All animal experiments were approved by the Institutional Animal Care and Use Committee (IACUC) of Indiana University. Details of materials, methods, and statistical analysis are included in the Supplementary files. 


\section{RESULTS}

\section{Liver-specific deletion of Atg5 altered the composition of GM}

Hepatic autophagy deficiency due to the deletion of a key autophagy gene, $\operatorname{Atg} 5$ or Atg7, causes significant liver injury, which is dependent on the nuclear factor erythroid 2-related factor 2 (NRF2) activation $[9,12,13]$. To investigate the impact of hepatic autophagy deficiency on GM, we first assessed the composition of GM in fecal samples from Atg5 $5^{\mathrm{F} / \mathrm{F}}$ and $\operatorname{Atg} 5^{\mathrm{\Delta hep}}$ mice by $16 \mathrm{~S}$ sequencing. Principal coordinates analysis showed that the composition of GM was noticeably separated between $\operatorname{Atg} 5^{5 / F}$ and $A \operatorname{tg} 5^{\wedge h e p}$ mice at the age of 8- or 16-week (Fig.1A). However, the diversity and the number of species were comparable between $\operatorname{Atg} 5^{\mathrm{F} / \mathrm{F}}$ and $\operatorname{Atg} 5^{\mathrm{Ahep}}$ mice (Fig.1B). The most abundant bacteria at the phylum level were Bacteroidetes, Firmicutes, and Proteobacteria, and their proportions were in general comparable between $\operatorname{Atg} 5^{\mathrm{F} / \mathrm{F}}$ and $\operatorname{Atg} 5^{\mathrm{\Delta hep}}$ mice (Fig. 1C). These results suggest that hepatic Atg5-deletion alters the proportion of bacterial species rather than the diversity of GM. Analysis at the genus level indeed showed significant disproportions of eight bacteria between $\operatorname{Atg} 5^{F / F}$ and $\operatorname{Atg} 5^{\Delta h e p}$ mice (Fig.1D). A higher proportion of Lactobacillus but a lower proportion of Prevotella, Paraprevotella, Turicibacter, Mogibacterium, and Ammonifex were observed in Atg5 $5^{\text {shep }}$ mice. The proportion of Johnsonella was also increased in most of the Atg $5^{\text {hep }}$ groups except the 16-week old female group. In addition, Parapedobacter seemed enriched only in the male Atg $5^{\text {\hep }}$ mice but impoverished in the females.

To understand whether the disproportion of GM was correlated with the autophagy deficiency, we analyzed GM in Atg $7^{\text {thep }}$ mice, another hepatic autophagy-deficiency mouse model. As observed in the $\operatorname{Atg} 5^{\Delta \text { hep }}$ mice, the diversity and the number of identified species were comparable between $\operatorname{Atg} 7^{\Delta \text { hep }}$ mice and their controls (Fig. S1A and B). However, proportions of nine genera were changed in Atg $7^{\text {thep }}$ mice (Fig. S1C), including Lactobacillus. These results indicate that hepatic autophagy deficiency can cause gut dysbiosis.

\section{$A B X$ treatment aggravated Atg5 deficiency-induced liver injury}


To investigate the potential impact of GM dysbiosis on the pathogenesis of hepatic autophagy deficiency, mice were given antibiotics (ABX) for 6 weeks (Fig.2A). ABX treatment did not affect either hepatic NRF2 activity (Fig. S2A and B), which could affect liver injury [12], or water consumption (Fig. $\mathrm{S} 2 \mathrm{C}$ ). The hepatomegaly in Atg5 $5^{\mathrm{hep}}$ mice remained unchanged following ABX treatment (Fig.2B and C). Nevertheless, gallbladders were enlarged following ABX treatment (Fig.2B and C), consistent with previous findings in germ-free mice [14]. Unexpectedly, serum levels of alanine transaminase (ALT), aspartate transaminase (AST), alkaline phosphatase (ALP), and total BA (TBA) were significantly increased in $A \operatorname{tg} 5^{\triangle \mathrm{hep}}$ mice but not significantly changed in $A \operatorname{tg} 5^{\mathrm{F} / \mathrm{F}}$ mice following $\mathrm{ABX}$ treatment (Fig. 2D). Consistently, $A B X$ treatment enhanced ductular reaction but not fibrotic reaction as shown by Haemotoxylin and Eosin (H\&E), cytokeratin 19 (CK19), and Masson's trichrome staining in Atg5deficient livers (Fig. 2E). Autophagy deficiency causes liver injury accompanied with cholestasis [11]. Consistently, Atg5 $5^{\Delta \text { hep }}$ mice presented increased TBA mainly in the liver and the feces (Fig. 2F). ABX treatment caused further elevations in TBA levels mainly in the intestine and the gallbladder, and thus the total BA pool elevated in $A \operatorname{tg} 5^{\mathrm{F} / \mathrm{F}}$ mice but more so in $A \operatorname{tg} 5^{\mathrm{Ahep}}$ mice (Fig. 2F). Similar to germ-free mice, accumulation of TBA in the intestine was accompanied with decreased fecal levels of TBA following $\mathrm{ABX}$ treatment (Fig. 2F). Overall, ABX treatment enhanced cholestatic liver injury of $A \operatorname{tg} 5^{\Delta \text { hep }}$ mice.

In Atg $7^{\Delta h e p}$ mice, ABX treatment increased TBA in the intestine and the total pool while decreased fecal excretion of TBA (Fig. S3A), the changes of which are similar to Atg5 $5^{\text {hep }}$ mice. However, hepatic enzyme levels in the blood were not further elevated in ABX-treated Atg $7^{\text {thep }}$ mice (Fig. S3B). This could be due to the well documented more severe liver injury seen in Atg $7^{\Delta h e p}$ mice (Fig. S3B and C v.s. Fig. 2C and D). The more severe phenotype of Atg7-deficient livers may mask the effects of $A B X$ treatment.

\section{BA-metabolizing bacteria were enriched in Atg $5^{\text {hep }}$ mice}


Since GM are critical for BA metabolism in the intestine $[15,16]$, we examined whether the disproportion of GM affected BA metabolism in $A t g 5^{\text {hep }}$ mice. The major BA-metabolizing bacteria are those that express bile salt hydrolase $(\mathrm{BSH})$ and/or $7 \alpha / \beta$-dehydroxylation activity, which include Lactobacillus, Bacteroides, Bifidobacterium, Eubacterium, and Clostridium [1]. Of note, unlike BSH activity, only a small number of bacteria belonging to the class Clostridia have $7 \alpha / \beta$-dehydroxylation activity [17]. A higher proportion of Lactobacillus (Fig. 1E) but not Clostridium or Eubacterium (Fig. 3A) was consistently found in $A \operatorname{tg} 5^{\text {hep }}$ mice. The elevation of Bacteroides was only observed in male Atg $5^{\text {\hep }}$ mice and that of Bifidobacterium was seen only in 16-week old Atg $5^{\text {hep }}$ mice (Fig. 3A). Thus, there were different levels of increments in BA-metabolizing bacteria in Atg5 $5^{\text {hep }}$ mice. In addition, we also observed an enrichment of Lactobacillus at genus level in $A \operatorname{tg} 7^{\Delta \mathrm{hep}}$ mice (Fig. S4A), suggesting that hepatic autophagy deficiency altered proportions of BA-metabolizing bacteria.

Further heterogeneity at the species levels within each of these five genera could be observed in term of the enrichment in $A \operatorname{tg} 5^{\Delta \text { hep }}$ mice. Since the variations could be related to the sex and/or the age, only a few species were overlapped between the cross-age/sex comparisons (Fig. S5A). Two heat maps based on the gender were then generated to include all disproportionated species, which presented the overall disproportion of the BA-metabolizing bacteria in Atg5 $5^{\Delta \text { hep }}$ mice (Fig. S5B). As

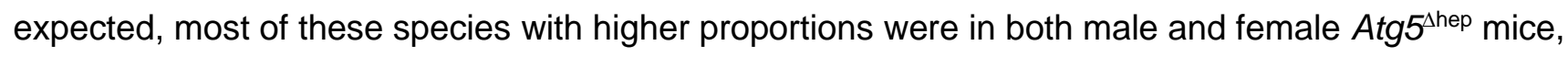
albeit with variations. We then focused on species that were disproportionately altered in both agematched male and female Atg5 $5^{\Delta \text { hep }}$ mice. We found that among the 7 species that were altered in 8week old $A \operatorname{tg} 5^{\Delta \text { hep }}$ mice, 6 of them were enriched (Set 1 in Fig. 3B). Similar enrichment of these species was seen in 16-week old Atg $5^{\text {hep }}$ mice although not statistically significant (Fig. 3B). On the other hand, in the 16-week old $A \operatorname{tg} 5^{\Delta \text { hep }}$ mice, 14 other species were disproportionated and 13 of them were enriched (Set 2 in Fig. 3B). We observed similar changes in $A t g 7^{\Delta h e p}$ mice. At species level, proportion of 9 species, including Bifidobacterium thermophilum, and another 8 from genus Lactobacillus, was enriched in Atg $7^{\text {hep }}$ mice (Fig. S4B). Overall, our results indicate that BA-metabolizing bacteria are 
enriched in hepatic autophagy-deficient mice at both genus and species levels, despite that there are age- and sex-related variations.

\section{Liver-specific deletion of Atg5 altered the composition of intestinal BAs}

As BA-metabolizing bacteria were enriched in $A \operatorname{tg} 5^{\Delta \text { hep }}$ mice, we interrogated the composition of BAs in the intestine and the liver. We found that the composition of intestinal BAs was distinctively separated among different groups (Fig. 3C-D). In the intestine, the total level of unconjugated BAs was elevated with a significant increase in CA in $A \operatorname{tg} 5^{\Delta \text { hep }}$ mice (Fig. 3E). Correspondingly, most of the tauro-conjugated BAs, either primary or secondary, were significantly reduced in Atg5 $5^{\text {hep }}$ mice (Fig. 3F). The composition of intestinal BAs suggested a stronger capacity of deconjugation in Atg $^{\text {shep }}$ mice. These observations are consistent with the higher proportion of BA-metabolizing bacteria in Atg $5^{\Delta \text { hep }}$ mice, which seemed to be more capable of deconjugation, but not necessary dehydroxylation. Following $\mathrm{ABX}$ treatment, we observed that the proportion of unconjugated BAs was dramatically increased whereas the proportion of conjugated BAs was decreased in both $\operatorname{Atg} 5^{\mathrm{F} / \mathrm{F}}$ and $\operatorname{Atg} 5^{\Delta \text { hep }}$ mice (Fig. 3E and F), the pattern of which is similar to the finding in germ-free mice [14]. Interestingly, Atg5 deletion in the liver did not change the effects of ABX on intestinal composition of BAs, which nondiscriminately eliminated BA-metabolizing bacteria for both deconjugation and dihydroxylation capability.

We then examined what potential impact of Atg5-deficiency and ABX treatment on hepatic BA compositions as comparisons. BA compositions in the liver were distinctly separable among the groups (Fig. S6A-B). As expected, the major BA species in the liver were the primary conjugated BAs (Fig. S6C-D). Despite total levels of both tauro-conjugated and unconjugated BAs did not seem to be affected significantly, individual BA composition showed changes that were associated with Atg5 deletion and/or ABX treatment. We observed a significant increase of taurocholic acid (TCA), but not tauromuricholic acid (TMCA), in Atg5-deficient livers (Fig. S6D). Hepatic levels of taurochenodeoxycholic acid (TCDCA), tauroursodeoxycholic acid (TUDCA), taurodeoxycholic acid 
(TDCA), and taurolithocholic acid (TLCA) were all decreased by Atg5-deletion (Fig. S6D). Following ABX treatment, hepatic levels of TCA and TCDCA were significantly decreased in $\operatorname{Atg} 5^{\mathrm{F} / \mathrm{F}}$ but not in Atg $5^{\mathrm{Ahep}}$ mice (Fig. S6D). Hepatic levels of TMCA- $(\alpha+\beta)$ and MCA- $\beta$ were significantly increased in $\operatorname{Atg} 5^{\mathrm{F} / \mathrm{F}}$ mice, which is similar to the case of germ-free mice [14], whereas the change was not observed in $A t g 5^{\Delta \text { hep }}$ mice (Fig. S6C-D). These results suggest that hepatic composition of BAs is altered but is less sensitive to $\mathrm{ABX}$ treatment in $\operatorname{Atg} 5^{\mathrm{\Delta hep}}$ mice [11].

\section{Ileal FXR activation and FGF15 expression was upregulated in Atg5 $5^{\text {hep }}$ mice in a manner dependent on GM}

Intestinal level of TMCA was significantly reduced in $A \operatorname{tg} 5^{\Delta \text { hep }}$ mice, which meanwhile was significantly affected by GM as indicated by the robust elevation following ABX treatment (Fig. 3F). Indeed, TMCA- $\beta$ in the intestine is known to particularly inhibit ileal FXR, which is activated by TCA [16]. Accumulation of TMCA- $\beta$ was found in germ-free mice and in conventional mice given $A B X$ treatment, which dramatically inhibited ileal FXR, which thereby reduced expression of FGF15 [14]. FGF15 is secreted into portal circulation to function as a hormone [18]. In the liver, FGF15 can inhibit BA synthesis when binding to its receptor FGFR4, which is critical for BA homeostasis [19, 20, 21, 22, 23].

We therefore hypothesized that the lower level of intestinal TMCA in $A \operatorname{tg} 5^{\Delta h e p}$ mice might allow a higher level of ileal FXR activation and a higher level of FGF15 expression. As expected, we found a significant increase of ileal expression of Fgf15 and small heterodimer partner (Shp) in Atg $5^{\Delta \text { hep }}$ mice, which is compromised by $A B X$ treatment (Fig. 4A), implying the involvement of TMCA. Fxr expression itself was not affected. In addition to Fgf15 and Shp, expression of intestinal BA transporters, which is regulated by FXR [24], is also affected by hepatic autophagy deficiency. In $\operatorname{Atg} 5^{\Delta \text { hep }}$ mice, ileal expression of both ileal bile acid-binding protein (Ibabp) and organic solute transporter subunit (Ost)- $\alpha$, but not Ost- $\beta$, was up-regulated, but compromised by ABX treatment (Fig. 4A). Ileal apical sodium-bile acid transporter (Asbt) expression was noticeably decreased in $A t g 5^{\Delta \text { hep }}$ mice (Fig. 4A). Following ABX 
treatment, expression of Mrp2 and Asbt was induced in mice of both genotypes (Fig. 4A). The pattern of gene expression indicates that the activation of ileal FXR in $A \operatorname{tg} 5^{\mathrm{Ahep}}$ mice can be compromised by ABX treatment, suggesting a potential association of these changes with GM.

The elevation of ileal FGF15 expression was further confirmed by immunoblotting (Fig. 4B and C) and immunochemistry (Fig. 4D), both of which were increased in $A t g 5^{\Delta \text { hep }}$ mice in a manner dependent on GM. Interestingly, ileal expression of Fgf15 and Ibabp was induced in Atg ${ }^{\text {hep }}$ mice, which was also compromised following ABX treatment (Fig. S7), suggesting that the modulation of ileal FXR activity by hepatic autophagy deficiency was not dependent on specific autophagy-related genes.

In order to examine the consequent impacts of FGF15 on Atg5-deficient livers, we analyzed FGF15-related pathways. In livers, FGF15 can bind to FGFR4 and activate the extracellular-signalregulated kinase (ERK) pathway [19]. As expected, phosphorylation level of ERK1/2 in Atg5-deficient livers was significantly induced but compromised following ABX treatment (Fig. 4E). Cyp7a1 gene that encodes the rate-limiting enzyme in the classical BA synthesis pathway is negatively regulated by FGF15 signaling [19]. Indeed, while Cyp7a1 mRNA level is low in Atg5 $5^{\text {hep }}$ livers, its expression was noticeably elevated following $A B X$ treatment (Fig. 4F), which is similar to the case in the germ-free mice [14] and consistent with the alteration in the FGF15 signaling. Expression of Fxr and most of its target genes was suppressed in Atg5-deficient liver as shown in our previous study [11] but not affected by ABX treatment (Fig. S8A-B).

Taken together, $A B X$ treatment affects the intestinal composition of $B A$, and eliminates the relative advantage of $A t g 5^{\Delta \text { hep }}$ mice in producing more ileal FGF15 due to a lower level of TMCA in the intestine.

\section{BAS reduced TBA pool but also ileal FGF15 production, leading to an enhanced Atg5 deficiency-induced liver injury}

Bile acid sequestrants (BAS) are large polymers that bind negatively charged bile acids in the small intestine, which can prevent reabsorption of bile acids in the gut, increase their fecal excretion, 
and finally disrupt enterohepatic circulation [25]. BAS is efficient to reduce TBA pool, however, evidence also shown that it can consequently inhibit ileal FXR and reduce expression of FGF15 in mice [26] and FGF19 in human [19]. To determine the impact of enterohepatic TBA on autophagy-deficient livers, mice were given cholestyramine resin treatment (Fig. 5A). As expected, a significant decrease of TBA levels in livers and enterohepatic circulation (Fig. 5B), and reduced gallbladder size (Fig. 5C) were observed in mice following BAS treatment. Although hepatomegaly in $\operatorname{Atg} 5^{\Delta \text { hep }}$ mice was not further enhanced (Fig. 5C), serum levels of ALT, AST, and ALP were all increased in Atg5 $5^{\Delta \text { hep }}$ mice following BAS treatment (Fig. 5D). H\&E staining showed an increased number of oval cells around the periportal areas in Atg5-deficient livers following BAS treatment (Fig. 5E). The increased positive areas of CK19 and Masson's trichrome staining indicate a more severe ductular reaction in Atg5-deficient livers following BAS treatment (Fig. 5E). These results suggest that BAS treatment in Atg $^{\Delta h e p}$ mice paradoxically enhances liver injury.

In order to identify potential mechanisms in which BAS treatment contributed to enhanced liver injury in $A \operatorname{tg} 5^{\Delta h e p}$ mice, we examined expression of FXR-regulated genes in both ileums and livers. Despite an increase of $F x r$ gene expression in $A \operatorname{tg} 5^{\mathrm{F} / \mathrm{F}}$ mice following BAS treatment, ileal expression of FXR-promoted genes, including Fgf15, Shp, Ibabp, Ost- $\alpha$, and Ost- $\beta$, was significantly reduced in mice following BAS treatment (Fig. 5F). The ileal level of Asbt mRNA, an FXR-suppressed gene, was increased following BAS treatment (Fig. 5F). These results suggested that ileal FXR activity was strongly inhibited by BAS treatment and consequently decreased expression of ileal Fgf15. In the liver, BAS treatment suppressed hepatic FXR activity in $A \operatorname{tg} 5^{\mathrm{F} / \mathrm{F}}$ mice but did not significantly change the expression of FXR targets in Atg $5^{\Delta h e p}$ mice (Fig. 5G), perhaps because the FXR activity was already reduced in autophagy deficient livers. Taken together, these results suggest that BAS treatment in Atg $5^{\Delta h e p}$ mice reduces ileal FXR activation and Fgf15 expression, which may contribute to the paradoxical effects on autophagy deficiency-induced liver injury.

\section{Intestine-specific FXR agonist activated ileal FXR in $A t g 5^{F / F}$ mice but not in Atg5 $5^{\Delta h e p}$ mice}


Since both ABX and BAS treatments exacerbate liver injury in Atg5 $5^{\mathrm{Ahep}}$ mice accompanied with reduced ileal FXR activity, we asked whether further activate ileal FXR can improve Atg5 deficiencyinduced liver injury. Hence, mice were given an intestine-specific FXR agonist, Fexaramine (FEX), for 7 days (Fig. S9A). Unexpectedly, FEX treatment did not change serum levels of ALT, AST, ALP, and TBA in $A t g 5^{\Delta h e p}$ mice, whereas serum level of TBA was decreased in Atg5 $5^{\mathrm{F} / \mathrm{F}}$ mice (Fig. S9B). Analysis of the expression of ileal Fxr and its target genes suggested an activation of FXR in $A \operatorname{tg} 5^{\mathrm{F} / \mathrm{F}}$ mice but not in $A t g 5^{\Delta \text { hep }}$ mice following FEX treatment (Fig. S9C). The TBA pool and fecal TBA level were both significantly reduced in $A \operatorname{tg} 5^{\mathrm{F} / \mathrm{F}}$ mice following FEX treatment, but not so much in $\operatorname{Atg} 5^{\mathrm{Ahep}}$ mice (Fig. S9D). The results suggest that altered GM and saturated FXR with existing BA agonists in Atg5 $5^{\Delta \text { hep }}$ mice may reduce the effects of FEX treatment in these mice. An early study also showed that GM could contribute to the efficacy of FEX treatment [27].

\section{Overexpression of FGF15 attenuated pathological features in Atg5 $5^{\text {hep }}$ livers}

FGF15 was significantly induced in $A t g 5^{\mathrm{Ahep}}$ mice but was reduced following treatments with $\mathrm{ABX}$ or BAS. We thus hypothesized that an elevated level of FGF15 could play a protective role in Atg5 deficiency-induced liver injury. Since recombinant FGF15 does not seem stable in the circulation for long-term experimentation [28, 29], AAV-FGF15 was given to Atg5 ${ }^{\text {hep }}$ mice (Fig. 6A). The level of phosphorylated ERK1/2 in the liver was elevated following AAV-FGF15 injection 1 week and 4-weeks later (Fig. 6B), suggesting that FGF15 signaling was enhanced in the liver as supported by a higher hepatic expression of Fgf15 (Fig. 6C). Consequently, hepatic levels of two classic targets of FGF15 signaling, Cyp7a1 and cytochrome p450 family 8b1 (Cyp8b1), were reduced following FGF15 overexpression (Fig. 6C). Paradoxically, hepatic Fxr and Shp expression was not elevated following FGF15 overexpression although the expression of bile salt export pump (Bsep), a direct target of FXR, was induced (Fig.6C), suggesting FXR-independent effects of FGF15 on hepatic gene expression. Consistent with the reduced expression of Cyp7a1 and Cyp8b1, the total TBA pool, mainly contributed by the intestinal level of BA, and the fecal TBA level were significantly reduced (Fig. 6D). 
Serum biochemistry analysis suggested FGF15 overexpression in the liver reduced ALP, but not ALT, AST, and TBA (Fig. 6E) in Atg5 $5^{\text {hep }}$ mice, suggesting a potential improvement in biliary injury. Consistently, the H-E staining and CK19 staining showed a reduced ductular reaction (Fig. 6F). On the other hand, the parameters of fibrosis (Fig. S10) showed a variable improvement to FGF15 overexpression, suggesting that the short treatment had a minor impact on this process.

\section{Inhibition of FGFR4 aggravated liver injury in Atg5 $5^{\Delta h e p}$ mice}

FGFR4 is the receptor that mediates FGF15 signaling in the liver [19]. In order to determine the role of FGF15-FGFR4 signaling in autophagy-deficient livers, we treated mice with Blu-9931 (BLU), a novel small molecular that selectively inhibits FGFR4 [30], to block FGFR4 activity (Fig. 7A).

Phosphorylated ERK1/2 level was decreased in Atg5-deficient livers following BLU treatment (Fig. 7B), suggesting FGF15-FGFR4 signaling was suppressed in the liver. In both $\operatorname{Atg} 5^{\mathrm{F} / \mathrm{F}}$ and $\operatorname{Atg} 5^{\mathrm{\Delta hep}}$ mice, BLU treatment reduced Shp expression whereas induced Cyp7a1 expression in the liver (Fig. 7C). Consequently, the TBA pool and fecal TBA level were significantly increased following BLU treatment (Fig. 7D), indicating an increase of BA synthesis in the liver. Consistently, with the inhibition of hepatic FGFR4, ileal expression of Fgf15 and Ibabp was remarkably induced following BLU treatment (Fig. 7E), which is possibly attributed to the increase of intestinal TBA.

Following BLU treatment, liver injury was enhanced in $A t g 5^{\Delta \text { hep }}$ mice as indicated by the significantly elevated serum levels of ALT, AST, and TBA (Fig. 7F). Notably, the male mice were more susceptible to BLU treatment for the serum enzyme activation (Fig. S11). We did not see significant pathological changes in livers of $A \operatorname{tg} 5^{F / F}$ mice (Fig. 7G), suggesting that inhibition of FGFR4 was not toxic in healthy livers. However, the ductular reaction around the periportal areas was further enhanced in Atg5-deficient livers following BLU treatment as indicated by H\&E staining and the positive areas of CK19 staining (Fig. 7G). Positive staining of Masson's Trichrome were also significantly increased in Atg5-deficient livers following BLU treatment (Fig. 7G). Although we found a noticeable sexual disparity in serum enzyme changes, changes in histological studies were comparable between male and female 
bioRxiv preprint doi: https://doi.org/10.1101/2020.05.12.090613; this version posted May 14, 2020. The copyright holder for this preprint (which was not certified by peer review) is the author/funder. All rights reserved. No reuse allowed without permission.

Atg $5^{\Delta \text { hep }}$ mice. Taken together, these results suggest that FGF15-FGFR4 signaling protects livers from further injury in Atg5-deficient mice. 


\section{DISCUSSION}

\section{Interaction between GM and hepatic autophagy deficiency and bile acid metabolism}

In this study, we showed that autophagy deficiency in the liver led to the alteration of intestinal BA composition and GM with a significantly higher proportion of BA-metabolizing bacteria. Unexpectedly, ABX treatment increased enterohepatic level of BAs and exacerbated the pathology in autophagydeficient livers. Together with other evidence, we demonstrate that enhanced activation of ileal FXRFGF15 signaling, due to the effects of altered BA metabolism and GM, is accounted for the protection of the autophagy-deficient liver from further injury (Fig. 8). Therefore gut dysbiosis in liver diseases can be an adaptive response to mitigate the injury via a gut-liver signaling pathway.

Autophagy deficiency in the liver causes hepatomegaly, chronic injury, and tumorigenesis [9, 10]. Mechanically, consistent activation of NRF2 by Sequestosome-1 (SQSTM1) is critical for pathological changes induced by hepatic Atg5 or Atg7-deletion [9, 12, 13], yet how SQSTM1-NRF2 signaling leads to hepatocyte death remains unclear. Our previous study shows a compromised FXR activity and altered BA homeostasis in autophagy-deficient livers [11], in which activation of FXR in the liver can ameliorate autophagy deficiency-induced liver injury, suggesting that reduced hepatic FXR expression and disrupted BA homeostasis may at least partially contribute to injury in autophagy-deficient livers.

In this study we have defined a unique interaction between GM and liver injury in the context of autophagy deficiency, which affects BA metabolism and gut-liver signaling. Firstly, we show that dysfunction of BA metabolism induced by Atg5 or Atg7 deficiency in the liver alters GM and leads to a significant enrichment of BA-metabolizing bacteria with BSH activity. GM is critical for BA metabolism by deconjugation of BAs and conversion of primary BAs into secondary BAs [6]. Consistent with enriched BA-metabolizing bacteria, we observed a lower level of tauro-conjugated BAs but a higher level of unconjugated BAs in the intestine. However, levels of most secondary BAs in the intestine are lower in Atg5 $^{\Delta \text { hep }}$ intestines except deoxycholic acid (DCA). In mice, DCA is converted from TCA, whereas other secondary BAs are converted from TCDCA [31]. Interestingly, TCDCA level is 
decreased in $A t g 5^{\text {hep }}$ livers, suggesting a reduced capability of CDCA synthesis in these mice, which may contribute to the decreased levels of non-DCA secondary BAs in the intestine. Overall, the evidence here suggests that autophagy deficiency in the liver alters hepatic BA metabolism, which generates a different BA profile and favors the growth of a specific set of GMs.

Secondly, we found that altered GM maintains the enterohepatic BA level. We have reported cholestatic injury in autophagy-deficient livers with a significant increase of TBA levels in serum and livers [11]. Here, we not only confirmed our previous findings but also found that despite the increase of hepatic TBA level, the enterohepatic TBA pool is comparable between $\operatorname{Atg} 5^{\mathrm{F} / \mathrm{F}}$ and $\operatorname{Atg} 5^{\Delta \text { hep }}$ mice (Fig. 2F). Increased fecal elimination was found in $A \operatorname{tg} 5^{\text {hep }}$ mice, which is reduced following $A B X$ treatment, suggesting that GM maintained enterohepatic level of TBA in $A \operatorname{tg} 5^{\text {hep }}$ mice by an increased BA excretion from the intestine. The mechanism of this increased excretion is not known, but could be related to a GM-dependent elevated ileal FXR activation, which needs to be further investigated in the future.

Thirdly, we present evidence that GM-mediated FXR activation in the ileum can induce FGF15 expression, thereby protecting mice from further liver damage caused by autophagy deficiency in the liver. Both the ABX and BAS treatments lead to a dramatic inhibition of ileal FXR activity and a significant decrease of FGF15 expression. Evidence from overexpression of FGF15 and inhibition of FGFR4 in the Atg5-deficient liver suggests that GM-mediated FGF15 expression at least partially protected $A t g 5^{\Delta \text { hep }}$ mice from further liver damage by a FGF15-FGFR4 feedback signaling pathway.

We previously found that $A \operatorname{tg} 7$ deletion induced more severe pathological changes than Atg5deletion in the liver, which leads to different response to alcohol treatment [32]. In this study, we also observed that $A B X$ treatment enhanced liver injury in $A t g 5^{\Delta \text { hep }}$ but not obviously in $A \operatorname{tg} 7^{\text {hep }}$ mice, despite increased BA pool and reduced ileal FXR activity following ABX treatment were observed in both $A \operatorname{tg} 5^{\text {hep }}$ and $A \operatorname{tg} 7^{\text {thep }}$ mice. It is possible that the protection effect from gut dysbiosis is overcome 
by additional hepatic phenotypes exerted by the more severe damage in the absence of Atg7, which sits on the upstream of Atg5 in the autophagy signaling pathway.

\section{Gut dysbiosis can be an adaptive response to liver injury}

A number of studies had shown that gut dysbiosis contributes to the progress of liver disease and correction of the dysbiosis may improve pathological changes in the liver [33, 34, 35, 36, 37]. Among the detriment effects of GM, "invasion" of the liver by the product of GM due to increased gut permeability is thought to be the leading cause [4]. While the detrimental role of gut dysbiosis seems to be a widely recognized, there is also evidence indicating a beneficial impact of GM on acute liver injury in mice. Enrichment of intestinal Lactobacillus was found in mice with liver injury induced by acute concanavalin A (Con A) treatment, which can prevent further liver inflammation through activation of IL22 production [38]. Furthermore, conflicting evidence supporting either a detrimental [39, 40] or beneficial $[14,41]$ effect of GM can be found for the liver injury in the ATP-binding cassette, sub-family B (MDR/TAP), member 4 (Mdr2) knockout $\left(M d r 2^{-/}\right)$mice.

In the present study, we have found GM is altered in Atg $5^{\Delta \text { hep }}$ mice. Surprisingly, ABX treatment enhanced Atg5 deficiency-induced liver injury, clearly indicating a protective role of GM in $\operatorname{Atg}^{\Delta \text { hep }}$ mice. We further identified an increase of FXR activity and ileal FGF15 expression in Atg $^{\Delta \text { hep }}$ mice, which is associated with the altered intestinal BA composition and the dysbiosis status of GM. Our finding demonstrates that FGF15 can be a beneficial feedback signal from gut dysbiosis attributed to hepatic autophagy deficiency.

In mice, FGF15 is induced by FXR activation in the ileum, and its human ortholog is FGF19 [18]. FGF15/19 is required for the efficiency of SHP-mediated CYP7A1 repression and plays a critical role in repressing BA synthesis [18]. Conversely, decrease of intestinal level of BA by BA sequestrants can reduce ileal FGF15 expression in mice [26] and serum FGF19 levels in healthy humans [42]. Animal experiments have shown that FGF15 is essential for hepatic homeostasis, and overexpression of FGF15/19 in the liver has beneficial effects on multiple liver diseases, including sclerosing cholangitis 
[20], alcoholic fatty liver [22], and NAFLD [21, 29]. In addition to its functions in hepatic metabolism, FGF15 has also been shown to contribute to liver regeneration [23, 43, 44]. In human, circulating FGF19 has been found to be increased in patients with biliary cirrhosis [45] and in patients with alcoholic hepatitis [46], which is accompanied with inhibition of BA synthesis. Nevertheless, the function and cause of increased levels of circulating FGF19 remains unclear. Our current finding of the beneficial effects of FGF15-FGFR4 signaling in autophagy-deficient livers provides evidence that increase of FGF15/19 level in the setting of liver diseases can potentially be a protective mechanism via the gut-liver interaction.

Our study suggests that GM can adapt to metabolic changes in the liver, and consequently activate feedback signaling, like FXR-FGF15 signaling, in the gut to protect the liver from further damage. The present study also suggests cautions should be exercised in the use of antibiotics during specific liver diseases to avoid potential detrimental effects, not due to reduced hepatic drug metabolism, but due to disruption of beneficial gut-liver signaling.

\section{CONCLUSION}

In summary, the findings in our studies indicate a primary liver disease can lead to alteration of GM, which then activates FXR-FGF15 feedback signaling through modulating the composition of intestinal BAs. Our results suggest that ABX treatment can exacerbate hepatic pathogenesis in Atg5deficient livers by the reduction of FGF15 expression. Taken together, our present study demonstrates a protective role of gut dysbiosis in liver injury, which is associated with the FXR-FGF15 feedback signaling. 
bioRxiv preprint doi: https://doi.org/10.1101/2020.05.12.090613; this version posted May 14, 2020. The copyright holder for this preprint (which was not certified by peer review) is the author/funder. All rights reserved. No reuse allowed without permission.

\section{ACKNOWLEDGEMENTS}

This work was supported in part by the USA National Institutes of Health (NIH) grants DK116605 (to X.-

M. Yin). 


\section{REFERENCES}

1 Nicholson JK, Holmes E, Kinross J, Burcelin R, Gibson G, Jia W, et al. Host-gut microbiota metabolic interactions. Science 2012;336:1262-7.

2 Schnabl B, Brenner DA. Interactions between the intestinal microbiome and liver diseases. Gastroenterology 2014;146:1513-24.

3 Bajaj JS. Alcohol, liver disease and the gut microbiota. Nat Rev Gastroenterol Hepatol 2019;16:235-46.

4 Tripathi A, Debelius J, Brenner DA, Karin M, Loomba R, Schnabl B, et al. The gut-liver axis and the intersection with the microbiome. Nat Rev Gastroenterol Hepatol 2018;15:397-411.

5 Li T, Chiang JY. Bile acids as metabolic regulators. Curr Opin Gastroenterol 2015;31:159-65.

6 Jia W, Xie G, Jia W. Bile acid-microbiota crosstalk in gastrointestinal inflammation and carcinogenesis. Nat Rev Gastroenterol Hepatol 2018;15:111-28.

7 Sabino J, Vieira-Silva S, Machiels K, Joossens M, Falony G, Ballet V, et al. Primary sclerosing cholangitis is characterised by intestinal dysbiosis independent from IBD. Gut 2016;65:1681-9. 8 Levine B, Kroemer G. Biological Functions of Autophagy Genes: A Disease Perspective. Cell 2019;176:11-42.

9 Komatsu M, Waguri S, Koike M, Sou YS, Ueno T, Hara T, et al. Homeostatic levels of p62 control cytoplasmic inclusion body formation in autophagy-deficient mice. Cell 2007;131:1149-63.

10 Takamura A, Komatsu M, Hara T, Sakamoto A, Kishi C, Waguri S, et al. Autophagy-deficient mice develop multiple liver tumors. Genes Dev 2011;25:795-800.

11 Khambu B, Li T, Yan S, Yu C, Chen X, Goheen M, et al. Hepatic Autophagy Deficiency Compromises Farnesoid X Receptor Functionality and Causes Cholestatic Injury. Hepatology 2019;69:2196-213.

12 Komatsu M, Kurokawa H, Waguri S, Taguchi K, Kobayashi A, Ichimura Y, et al. The selective autophagy substrate p62 activates the stress responsive transcription factor Nrf2 through inactivation of Keap1. Nat Cell Biol 2010;12:213-23.

13 Ni HM, Woolbright BL, Williams J, Copple B, Cui W, Luyendyk JP, et al. Nrf2 promotes the development of fibrosis and tumorigenesis in mice with defective hepatic autophagy. J Hepatol 2014;61:617-25.

14 Sayin SI, Wahlstrom A, Felin J, Jantti S, Marschall HU, Bamberg K, et al. Gut microbiota regulates bile acid metabolism by reducing the levels of tauro-beta-muricholic acid, a naturally occurring FXR antagonist. Cell Metab 2013;17:225-35.

15 Ridlon JM, Kang DJ, Hylemon PB. Bile salt biotransformations by human intestinal bacteria. J Lipid Res 2006;47:241-59. 
16 Wahlstrom A, Sayin SI, Marschall HU, Backhed F. Intestinal Crosstalk between Bile Acids and Microbiota and Its Impact on Host Metabolism. Cell Metab 2016;24:41-50.

17 Urdaneta V, Casadesus J. Interactions between Bacteria and Bile Salts in the Gastrointestinal and Hepatobiliary Tracts. Front Med (Lausanne) 2017;4:163.

18 Kliewer SA, Mangelsdorf DJ. Bile Acids as Hormones: The FXR-FGF15/19 Pathway. Dig Dis 2015;33:327-31.

19 Gadaleta RM, Moschetta A. Metabolic Messengers: fibroblast growth factor 15/19. Nature Metabolism 2019;1:588-94.

20 Zhou M, Learned RM, Rossi SJ, DePaoli AM, Tian H, Ling L. Engineered fibroblast growth factor 19 reduces liver injury and resolves sclerosing cholangitis in Mdr2-deficient mice. Hepatology 2016;63:914-29.

21 Zhou M, Luo J, Chen M, Yang H, Learned RM, DePaoli AM, et al. Mouse species-specific control of hepatocarcinogenesis and metabolism by FGF19/FGF15. J Hepatol 2017;66:1182-92.

22 Hartmann P, Hochrath K, Horvath A, Chen P, Seebauer CT, Llorente C, et al. Modulation of the intestinal bile acid/farnesoid $X$ receptor/fibroblast growth factor 15 axis improves alcoholic liver disease in mice. Hepatology 2018;67:2150-66.

23 Kong B, Sun R, Huang M, Chow MD, Zhong XB, Xie W, et al. Fibroblast Growth Factor 15Dependent and Bile Acid-Independent Promotion of Liver Regeneration in Mice. Hepatology 2018;68:1961-76.

24 Dawson PA. Role of the intestinal bile acid transporters in bile acid and drug disposition. Handb Exp Pharmacol 2011:169-203.

25 Out C, Groen AK, Brufau G. Bile acid sequestrants: more than simple resins. Curr Opin Lipidol 2012;23:43-55.

26 Fuchs CD, Paumgartner G, Mlitz V, Kunczer V, Halilbasic E, Leditznig N, et al. Colesevelam attenuates cholestatic liver and bile duct injury in Mdr2(-/-) mice by modulating composition, signalling and excretion of faecal bile acids. Gut 2018;67:1683-91.

27 Pathak P, Xie C, Nichols RG, Ferrell JM, Boehme S, Krausz KW, et al. Intestine farnesoid X receptor agonist and the gut microbiota activate G-protein bile acid receptor-1 signaling to improve metabolism. Hepatology 2018;68:1574-88.

28 Luo J, Ko B, Elliott M, Zhou M, Lindhout DA, Phung V, et al. A nontumorigenic variant of FGF19 treats cholestatic liver diseases. Sci Transl Med 2014;6:247ra100.

29 Alvarez-Sola G, Uriarte I, Latasa MU, Fernandez-Barrena MG, Urtasun R, Elizalde M, et al. Fibroblast growth factor 15/19 (FGF15/19) protects from diet-induced hepatic steatosis: development of an FGF19-based chimeric molecule to promote fatty liver regeneration. Gut 2017;66:1818-28. 
30 Hagel M, Miduturu C, Sheets M, Rubin N, Weng W, Stransky N, et al. First Selective Small Molecule Inhibitor of FGFR4 for the Treatment of Hepatocellular Carcinomas with an Activated FGFR4 Signaling Pathway. Cancer Discov 2015;5:424-37.

31 Chiang JYL, Ferrell JM. Bile Acids as Metabolic Regulators and Nutrient Sensors. Annu Rev Nutr 2019;39:175-200.

32 Yan S, Zhou J, Chen X, Dong Z, Yin XM. Diverse Consequences in Liver Injury in Mice with Different Autophagy Functional Status Treated with Alcohol. Am J Pathol 2019;189:1744-62.

33 De Minicis S, Rychlicki C, Agostinelli L, Saccomanno S, Candelaresi C, Trozzi L, et al. Dysbiosis contributes to fibrogenesis in the course of chronic liver injury in mice. Hepatology 2014;59:1738-49. 34 Jena PK, Sheng L, Liu HX, Kalanetra KM, Mirsoian A, Murphy WJ, et al. Western Diet-Induced Dysbiosis in Farnesoid $X$ Receptor Knockout Mice Causes Persistent Hepatic Inflammation after Antibiotic Treatment. Am J Pathol 2017;187:1800-13.

35 Ferrere G, Wrzosek L, Cailleux F, Turpin W, Puchois V, Spatz M, et al. Fecal microbiota manipulation prevents dysbiosis and alcohol-induced liver injury in mice. J Hepatol 2017;66:806-15. 36 Grander C, Adolph TE, Wieser V, Lowe P, Wrzosek L, Gyongyosi B, et al. Recovery of ethanolinduced Akkermansia muciniphila depletion ameliorates alcoholic liver disease. Gut 2018;67:891-901. 37 Chen P, Starkel P, Turner JR, Ho SB, Schnabl B. Dysbiosis-induced intestinal inflammation activates tumor necrosis factor receptor I and mediates alcoholic liver disease in mice. Hepatology 2015;61:883-94.

38 Nakamoto N, Amiya T, Aoki R, Taniki N, Koda Y, Miyamoto K, et al. Commensal Lactobacillus Controls Immune Tolerance during Acute Liver Injury in Mice. Cell Rep 2017;21:1215-26.

39 Tedesco D, Thapa M, Chin CY, Ge Y, Gong M, Li J, et al. Alterations in Intestinal Microbiota Lead to Production of Interleukin 17 by Intrahepatic gammadelta T-Cell Receptor-Positive Cells and Pathogenesis of Cholestatic Liver Disease. Gastroenterology 2018;154:2178-93.

40 Liao L, Schneider KM, Galvez EJC, Frissen M, Marschall HU, Su H, et al. Intestinal dysbiosis augments liver disease progression via NLRP3 in a murine model of primary sclerosing cholangitis. Gut 2019;68:1477-92.

41 Tabibian JH, O'Hara SP, Trussoni CE, Tietz PS, Splinter PL, Mounajjed T, et al. Absence of the intestinal microbiota exacerbates hepatobiliary disease in a murine model of primary sclerosing cholangitis. Hepatology 2016;63:185-96.

42 Lundasen T, Galman C, Angelin B, Rudling M. Circulating intestinal fibroblast growth factor 19 has a pronounced diurnal variation and modulates hepatic bile acid synthesis in man. $\mathrm{J}$ Intern Med 2006;260:530-6.

43 Uriarte I, Fernandez-Barrena MG, Monte MJ, Latasa MU, Chang HC, Carotti S, et al. Identification of fibroblast growth factor 15 as a novel mediator of liver regeneration and its application in the prevention of post-resection liver failure in mice. Gut 2013;62:899-910. 
44 Kong B, Huang J, Zhu Y, Li G, Williams J, Shen S, et al. Fibroblast growth factor 15 deficiency impairs liver regeneration in mice. Am J Physiol Gastrointest Liver Physiol 2014;306:G893-902.

45 Li Z, Lin B, Lin G, Wu Y, Jie Y, Li X, et al. Circulating FGF19 closely correlates with bile acid synthesis and cholestasis in patients with primary biliary cirrhosis. PLoS One 2017;12:e0178580.

46 Brandl K, Hartmann P, Jih LJ, Pizzo DP, Argemi J, Ventura-Cots M, et al. Dysregulation of serum bile acids and FGF19 in alcoholic hepatitis. J Hepatol 2018;69:396-405. 


\section{FIGURE LEGENDS}

Fig. 1 Liver-specific deletion of Atg5 altered the composition of GM. (A). Principal coordinates analysis (PCoA) based on relative abundance at species level shows a distinguishable profile of GM between 8- and 16- weeks old $A \operatorname{tg} 5^{F / F}$ and Atg5 $5^{\triangle h e p}$ mice. Data from mice of both sexes were plotted. (B). Shannon species diversity and number of species identified were similar among different groups of mice. (C). Proportion of three most abundant bacteria at phylum level. (D). Proportion of bacteria that showed significant changes in at least three comparisons between the age- and sex- matched $\operatorname{Atg} 5^{F / F}$ and $\operatorname{Atg} 5^{\Delta h e p}$ mice at the genus level. Data were shown as median with interquartile range, $\mathrm{n}=10 /$ group. Mann-Whitney analysis was used to determine significance, ${ }^{*} p<0.05$.

Fig. 2 ABX treatment aggravated Atg5 deficiency-induced liver injury. (A). Scheme of the antibiotics $(A B X)$ treatment. Mice were given neomycin sulfate and ampicillin sodium salt mixture in daily drinking water for 6 weeks. (B). Representative gross anatomy of livers of indicated genotypes and treatments. (C). Liver weight and gallbladder (Gal) weight were determined as percentages of the body weight ( $n=10-16 /$ group). (D). The serum levels of ALT, AST, ALP, and TBA in mice ( $n=10$ 16/group). (E). Liver sections were subjected to H\&E, anti-CK19, or Masson's trichrome staining. Percentage of positive area was quantified with ImageJ (anti-CK19 staining quantification, n=3-4/group; Masson's trichrome staining quantification, $n=8-12$ /group). (F). TBA levels in indicated compartments were measured ( $n=7-16 /$ group). Data were shown as means \pm S.E. Groups with different letters had significant differences $(p<0.05)$. ALT, alanine transaminase; ALP, alkaline phosphatase; AST, aspartate transaminase; CK19, cytokeratin 19; TBA, total bile acids.

\section{Fig. 3 Hepatic autophagy deficiency affect intestinal BA composition in correlation with gut}

dysbiosis. (A). Hepatic autophagy deficiency affected the proportion of bacteria with the bile salt hydrolase and/or $7 \alpha / \beta$-dehydroxylation activities at the genus level (Lactobacillus is shown in Fig.1E). Data were shown as median with interquartile range, $n=10$ /group. (B). The heatmap shows the BAmetabolizing bacteria that are disproportionated in $A \operatorname{tg} 5^{\Delta h e p}$ mice at the species level. Heatmap was 
generated and values in the heatmap were mapped to colors using the minimum and maximum of each row independently. The hierarchical cluster of different species was constructed using one minus Pearson correlation method. Proportion of bacteria in Set 1 was significantly changed in both male and female $\operatorname{Atg} 5^{\Delta h e p}$ mice at 8 weeks old. Proportion of bacteria in Set 2 was significantly changed in both male and female $A \operatorname{tg} 5^{\Delta h e p}$ mice at 16 weeks old. (C). PCoA analysis of BAs in the intestine data (log2scaled $\mu \mathrm{M})$. (D). Heatmap was generated and values in the heatmap were mapped to colors using the minimum and maximum of each row independently. The heatmap shows the cluster of indicated BA species in the intestine of different groups of mice. The hierarchical cluster of different BAs was constructed using one minus Pearson correlation method. (E-F) The intestinal levels of unconjugated (E) and tauro-conjugated (F) bile acids in male mice. Data were shown as percentage of TBA level (means \pm S.E), $n=5$ /group. Groups with different letters or indicated by asterisk had significant differences $(p<0.05)$. CA, cholic acid; CDCA, chenodeoxycholic acid; DCA, deoxycholic acid; HDCA, hyodeoxycholic acid; LCA, lithocholic acid; MCA,muricholic acid; TCA, taurocholic acid; TCDCA, taurochenodeoxycholic acid; TDCA, taurodeoxycholic acid; TLCA, taurolithocholic acid; TMCA, tauromuricholic acid; TUDCA, tauroursodeoxycholic acid; UDCA, ursodeoxycholic acid.

Fig. 4 GM regulates ileal FXR activation and FGF15 expression in $\boldsymbol{A t g}^{\triangle h e p}$ mice. (A). mRNA level of indicated genes in the ileum was analyzed by qRT-PCR ( $n=7-9 / g r o u p)$. (B-C). Ileal FGF15 protein levels were examined by immunoblotting assay (B), and quantified with densitometry (C, $n=3 /$ group). (D). Representative images of anti-FGF15 immunohistochemistry staining in the ileum of indicated genotypes and treatments. (E). ERK1/2 level in the liver was analyzed by immunoblotting assay, and quantified by densitometry. Phosphorylation level of ERK1/2 was normalized by the total protein level and expressed as the fold change of the $A \operatorname{tg} 5^{\mathrm{F} / \mathrm{F}}$ control group ( $\left.\mathrm{n}=5-7 / \mathrm{group}\right)$. (F). Expression of Cyp7a1 was analyzed by qRT-PCR in the liver ( $\mathrm{n}=6-9 /$ group). Data were shown as means \pm S.E. Groups with different letters had significant differences $(p<0.05)$. N.S. indicates no statistical significance. Asbt (Slc10a2), apical sodium-bile acid transporter; Cyp7a1, cytochrome P450 7a1; ERK, extracellular-signal-regulated kinase; Fgf15, fibroblast growth factor 15; Fxr, farnesoid X 
receptor; Ibabp, ileal bile acid-binding protein; Mrp2 (Abcc2), multidrug resistance-associated protein 2; Mrp3 (Abcc3), multidrug resistance-associated protein 3; Ost- $\alpha(S / c 51 A)$, organic solute transporter subunit $\alpha$; Ost- $\beta(S / c 51 B)$, organic solute transporter subunit $\beta$; Shp, small heterodimer partner.

Fig. 5 BAS reduced TBA pool but enhanced Atg5 deficiency-induced liver injury. (A). Scheme of the bile acid sequestrant (BAS) treatment. Water was given as control. (B). TBA levels in the indicated compartments were measured ( $n=6-8 /$ group). (C). Liver weight and gallbladder (Gal) weight were determined as percentage of the body weight ( $n=6-8 /$ group). (D). The serum levels of ALT, AST, ALP, and TBA in mice following BAS treatment ( $n=6-8$ /group). (E). Liver sections were subjected to H\&E, anti-CK19, or Masson's trichrome staining. Percentage of positive area was quantified with ImageJ (anti-CK19 staining quantification, n=3-4/group; Masson's trichrome staining quantification, $\mathrm{n}=3$ 5/group). (F-G). Expression of genes related to BA metabolism in ileums (F) or in livers (G) was analyzed by qRT-PCR ( $n=4-6 /$ group). Data were shown as means \pm S.E. Groups with different letters had significant differences $(p<0.05)$. ALT, alanine transaminase; ALP, alkaline phosphatase; AST, aspartate transaminase; Asbt (Slc10a2), apical sodium-bile acid transporter; Bsep (Abcb11), bile salt export pump; Cyp7a1, cytochrome P450 7a1; CK19, cytokeratin 19; Fgf15, fibroblast growth factor 15; Fgfr4, fibroblast growth factor receptor 4; Fxr, farnesoid X receptor; Ibabp, ileal bile acid-binding protein; Mrp2 (Abcc2), multidrug resistance-associated protein 2; Mrp3 (Abcc3), multidrug resistanceassociated protein 3; Mrp4 (Abcc4), multidrug resistance-associated protein 4; Ntcp (Slc10a1), $\mathrm{Na}$ /Taurocholate cotransporting polypeptide; Oatp1 (Slco1a1), organic anion-transporting polypeptide 1; Ost- $\alpha(S / c 51 A)$, organic solute transporter subunit $\alpha$; Ost- $\beta$ (S/c51B), organic solute transporter subunit $\beta$; Shp, small heterodimer partner; TBA, total bile acids.

Fig. 6 Overexpression of FGF15 attenuated pathological features in $\operatorname{Atg}^{\Delta h e p}$ livers. (A). Scheme of the FGF15 overexpression study in mouse livers. (B). Expression of ERK1/2 in the liver were analyzed by immunoblotting assay and quantified by densitometry. Phosphorylation levels of ERK1/2 were normalized to that of the total protein levels and expressed as fold change of GFP group ( $n=8 /$ group). (C). Hepatic expression of indicated genes was analyzed by qRT-PCR ( $n=3-5 / g r o u p)$. 
Data was expressed as fold change of GFP for the 1-week group. (D). TBA levels in the indicated compartments were measured ( $n=3-5 /$ group). (E). The serum levels of ALT, AST, ALP, and TBA in mice following AAV-injection ( $n=3-5 /$ group). (F). Liver sections were subjected to H\&E, anti-CK19, or Masson's trichrome staining. Percentage of positive area was quantified with ImageJ ( $n=3-5 / g r o u p)$. Data were shown as means \pm S.E. ${ }^{*} p<0.05,{ }^{* *} p<0.01$. AAV, adeno-associated virus; ALT, alanine transaminase; ALP, alkaline phosphatase; AST, aspartate transaminase; $B s e p(A b c b 11)$, bile salt export pump; CK19, cytokeratin 19; Cyp7a1, cytochrome P450 7a1; Cyp8b1, cytochrome p450 8b1; ERK, extracellular-signal-regulated kinase; Fgf15, fibroblast growth factor 15; Fxr, farnesoid X receptor; Shp, small heterodimer partner; TBA, total bile acids.

Fig. 7 Inhibition of FGFR4 aggravated liver injury in $\operatorname{Atg}^{\Delta \text { hep }}$ mice. (A). Scheme of, the treatment with FGFR4 inhibitor, Blu-9931 (BLU). Solvent (0.5\% methylcellulose/1\% Tween 80) was given as control. (B). The levels of ERK1/2 were examined by immunoblotting assay, and quantified by densitometry ( $n=3-5 /$ group). The phosphorylation level of ERK1/2 was normalized to that of the total protein level and expressed as the fold change of $A \operatorname{tg} 5^{\mathrm{F} / \mathrm{F}}$ control group. (C). Hepatic expression of indicated genes was analyzed by qRT-PCR ( $n=4-7 /$ group). (D). TBA levels in indicated compartments were measured ( $n=6-8 /$ group). (E). Ileal expression of indicated genes was analyzed by qRT-PCR ( $n=4-6 /$ group). (F). The serum levels of ALT, AST, ALP, and TBA in mice following BLU-treatment (n=6-8/group). (G). Liver sections were subjected to H\&E, anti-CK19, or Masson's trichrome staining. Percentage of positive area was quantified with ImageJ (CK19 staining quantification, n=3-6/group; Masson's trichrome staining quantification, $n=4-5 /$ group). Data were shown as means \pm S.E. Groups with different letters had significant differences $(p<0.05)$. N.S. indicates no statistical significance. ALT, alanine transaminase; ALP, alkaline phosphatase; AST, aspartate transaminase; Asbt (Slc10a2), apical sodium-bile acid transporter; Bsep (Abcb11), bile salt export pump; CK19, cytokeratin 19; Cyp7a1, cytochrome P450 7a1; ERK, extracellular-signal-regulated kinase; Fgf15, fibroblast growth factor 15; Fgfr4, fibroblast growth factor receptor 4; Fxr, farnesoid X receptor; Ibabp, ileal bile acidbinding protein; Shp, small heterodimer partner; TBA, total bile acids. 


\section{Fig. 8 GM-dependent FXR-FGF15 signaling improves hepatic presentation in Atg5-deficient}

mice. Atg5 deficiency in the liver impairs autophagy process and BA homeostasis, which causes liver injury accompanied with cholestasis. Disruption of hepatic BA homeostasis altered the composition of BAs in the intestine, and gut microbiota, which in turn affects BA composition in the intestine. The changes in intestinal BA composition activates ileal FXR, and consequently induces FGF15 expression and reduces BA uptake in the intestine, both of which can improve the homeostasis of enterohepatic BA. Importantly, FGF15 is beneficial to the improvement of the liver injury induced by autophagy deficiency. Atg5, autophagy-related gene 5; BA, bile acid; FGF15, fibroblast growth factor 15; FXR, farnesoid $\mathrm{X}$ receptor. 
Fig. 1

A

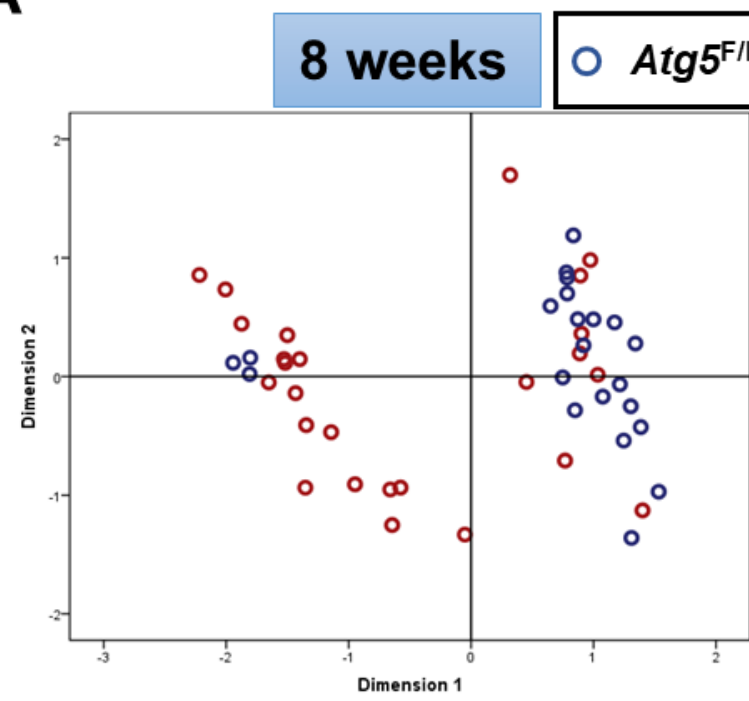

C

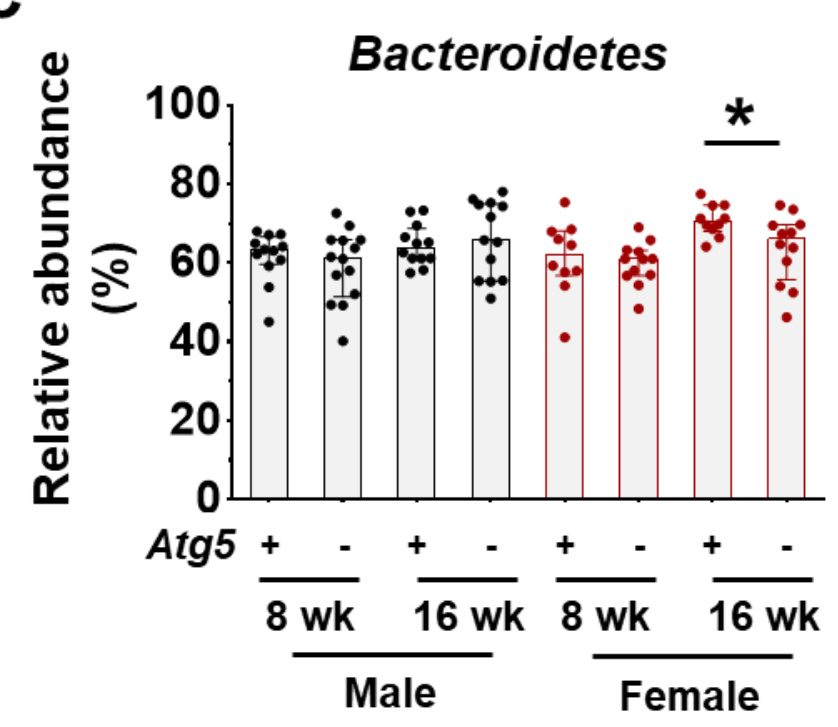

\section{$\circ$ Atg $^{\text {मhep }} 16$ weeks}

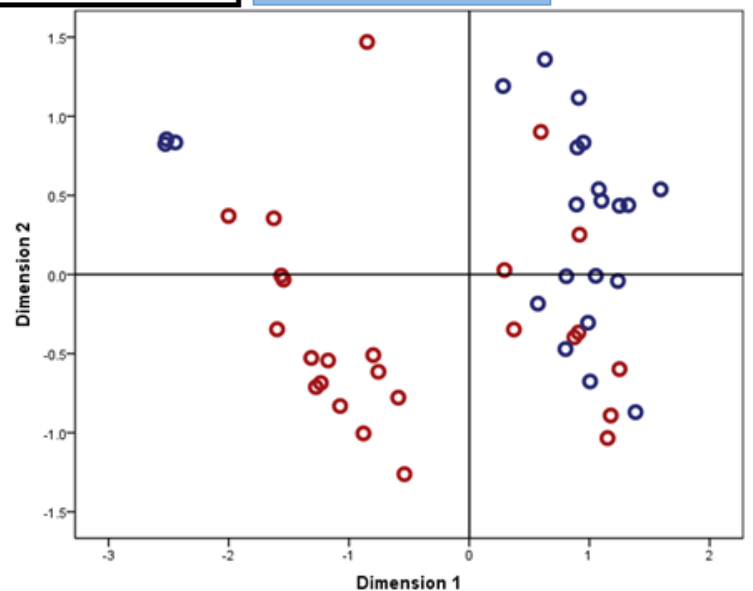

Firmicutes

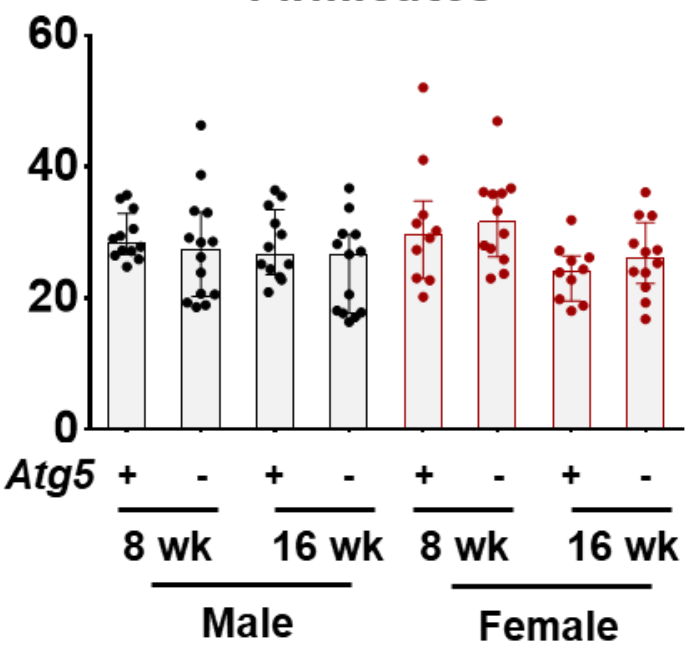

B
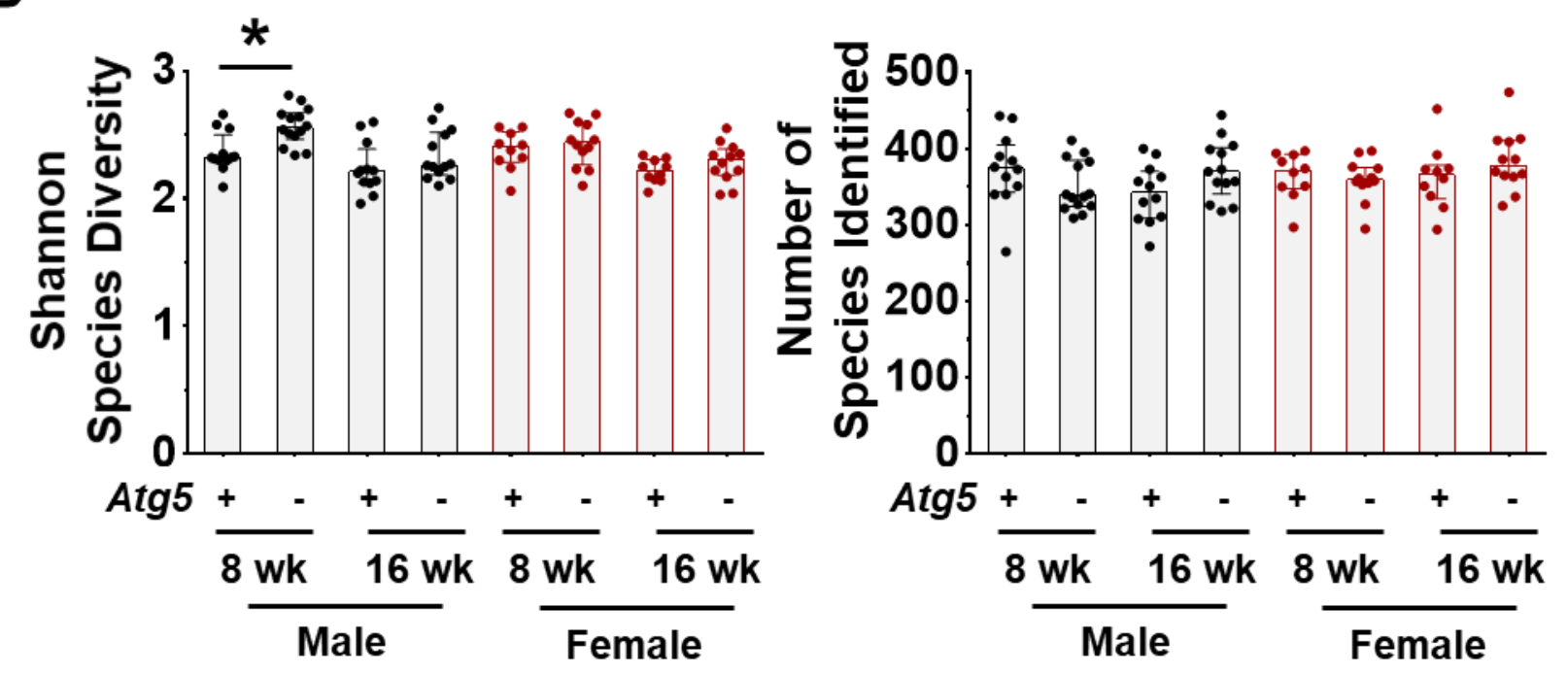

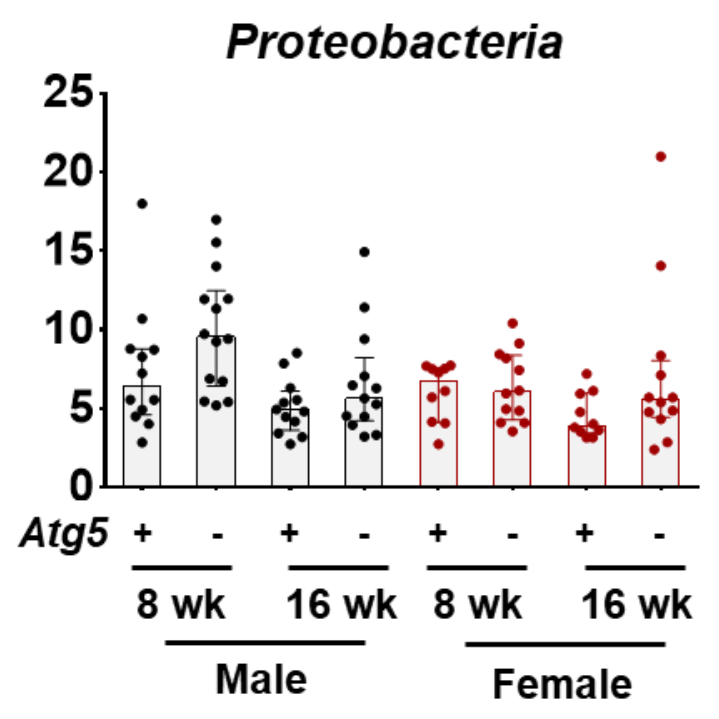


D
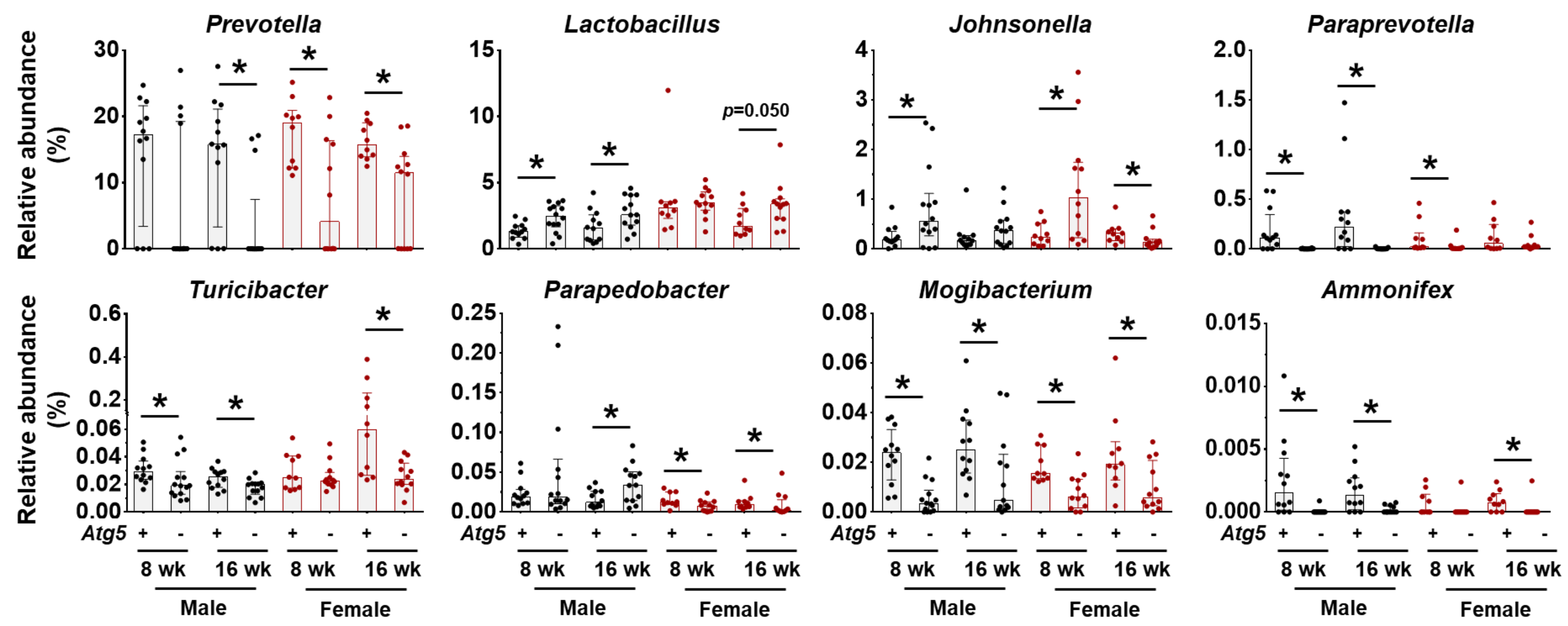
A

D
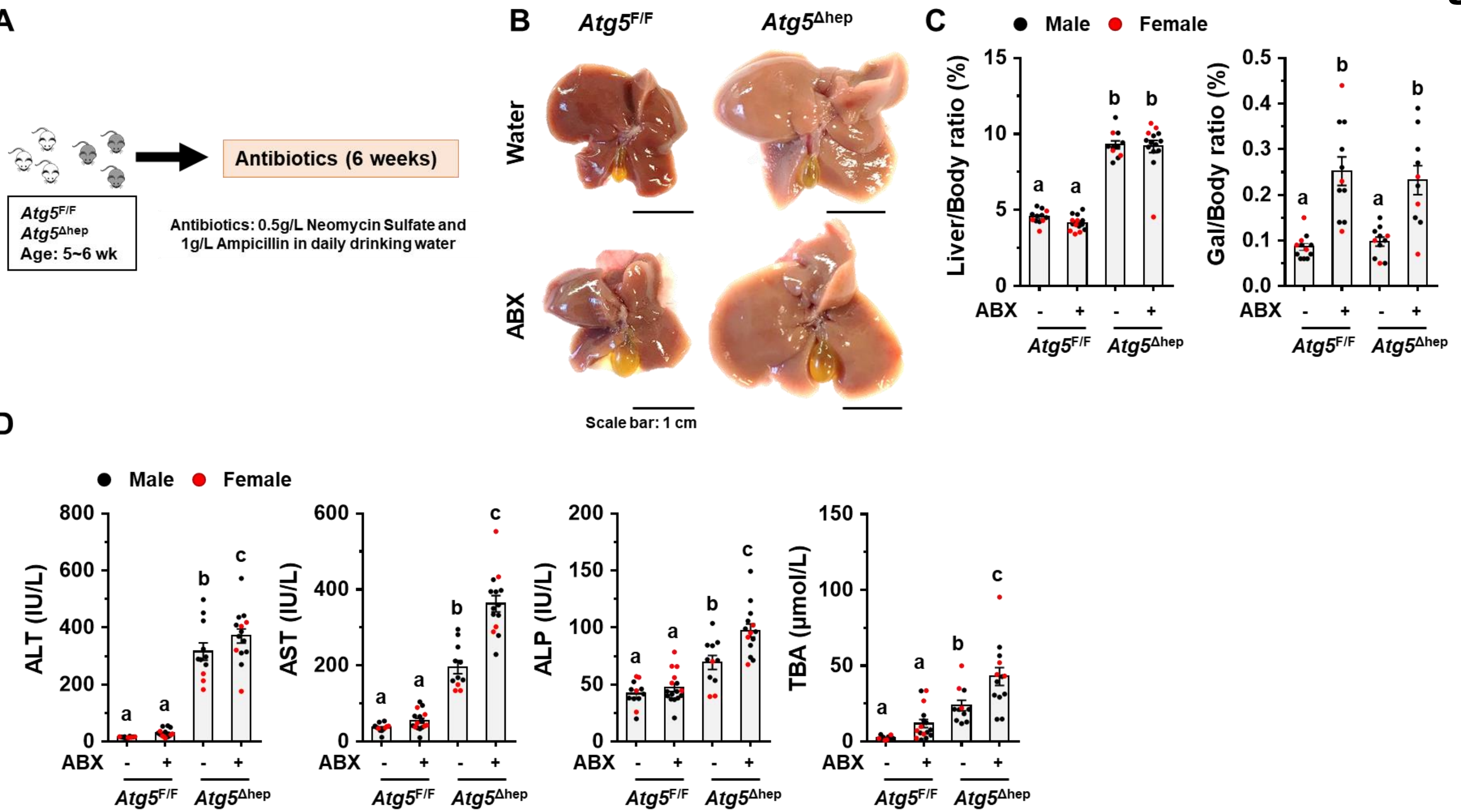

C - Male $\bullet$ Female
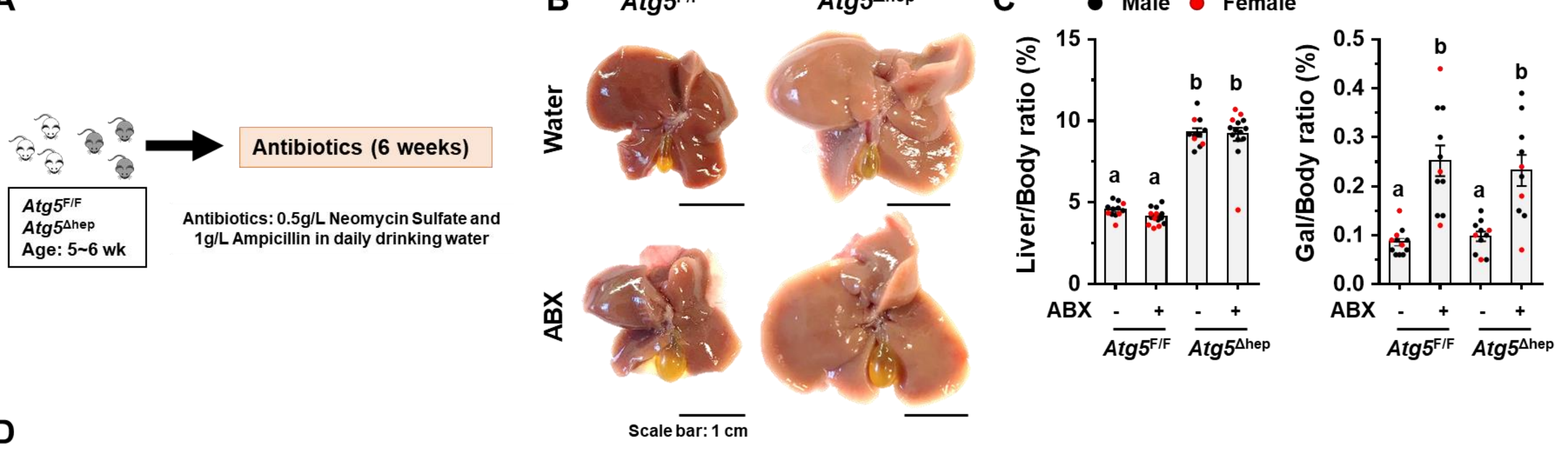

Fig. 2 
Fig. 2

E
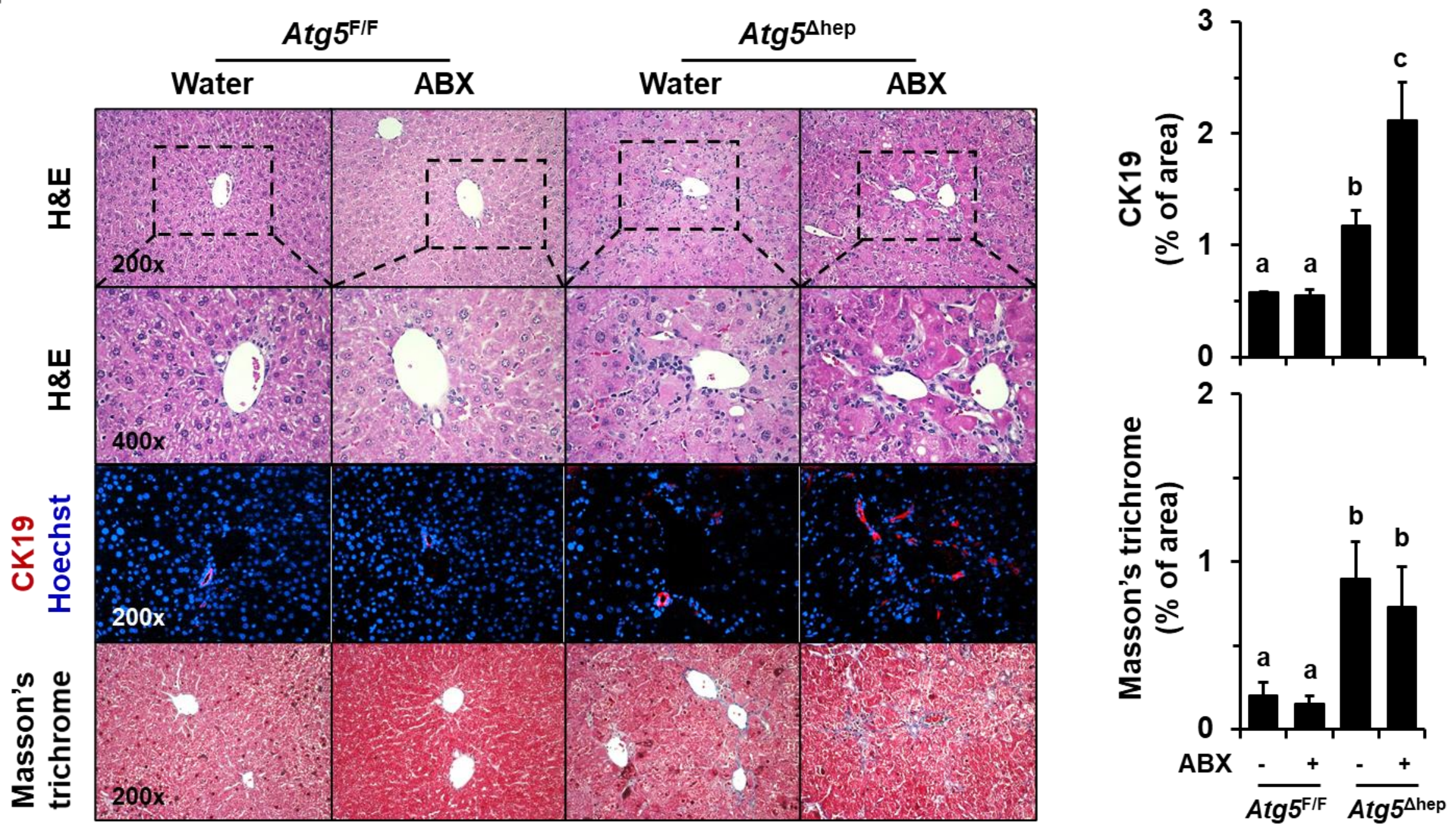


\section{F}

\section{Enterohepatic TBA}

Female

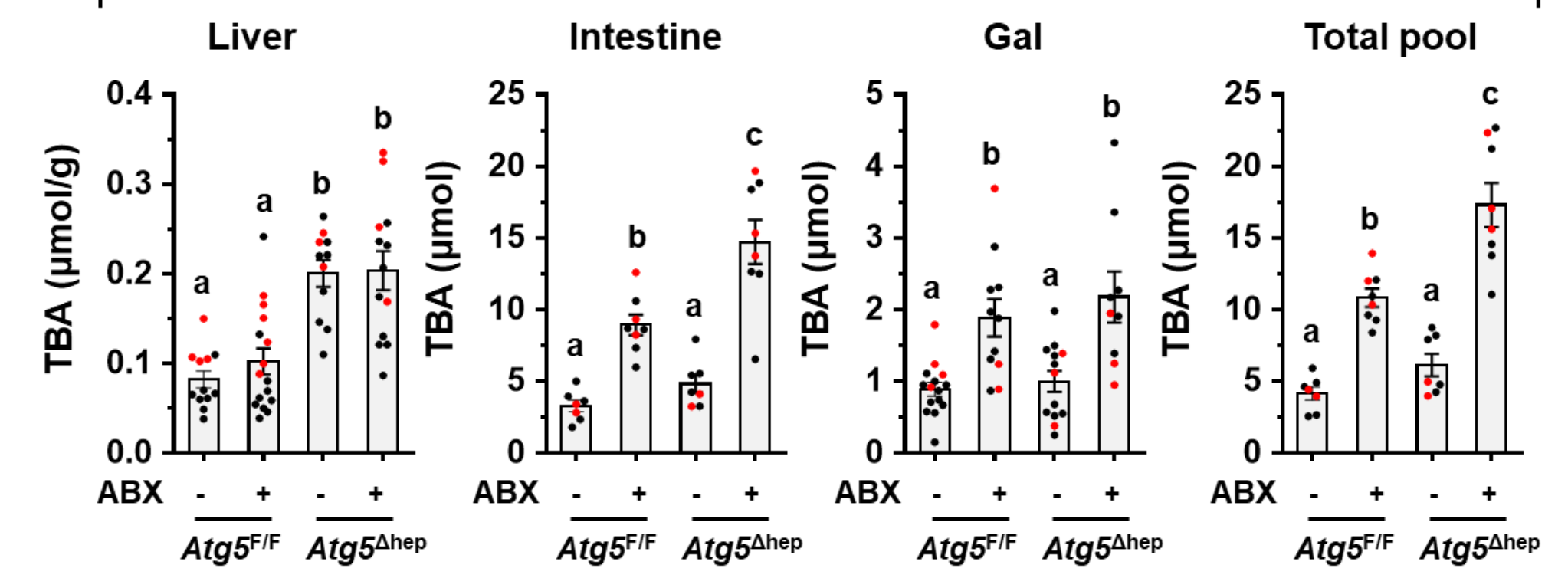

Gal

Total pool

Feces

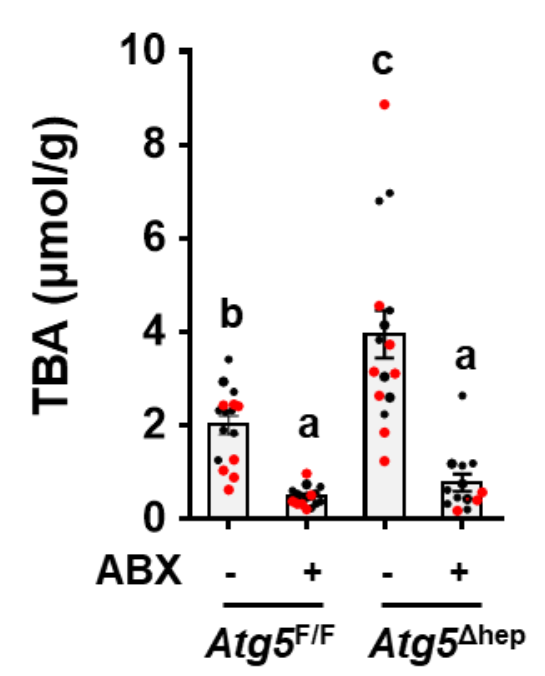


Fig. 3

A

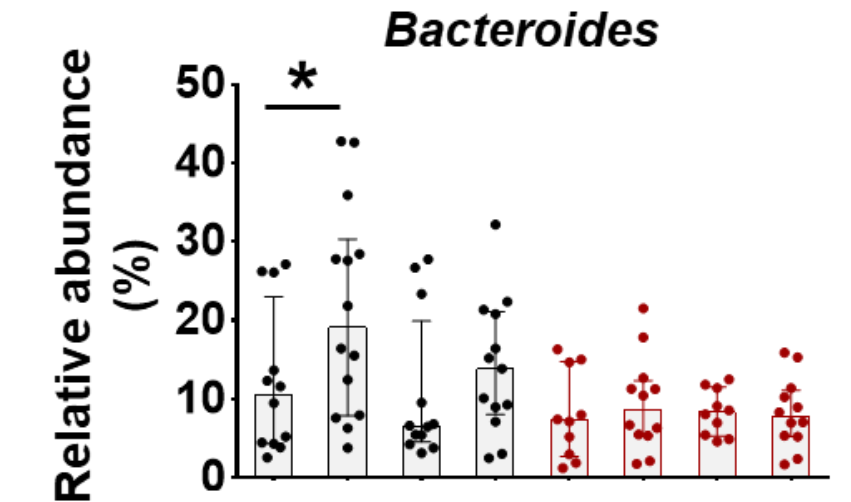

Eubacterium

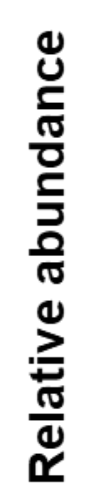

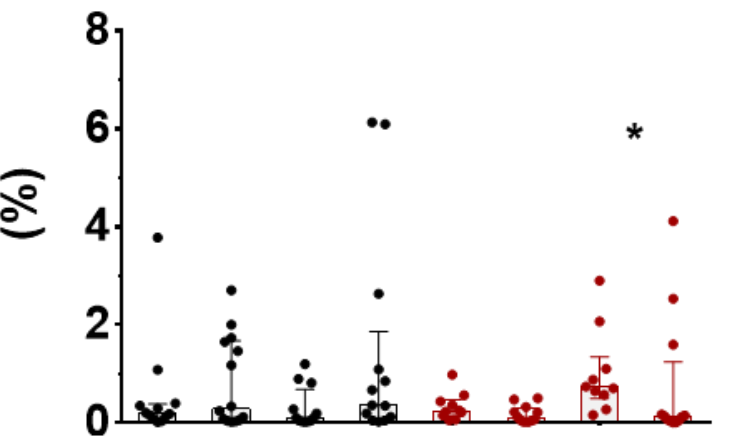

Atg5 +

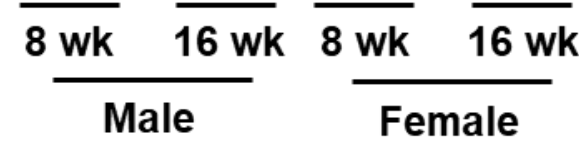

B

Bifidobacterium

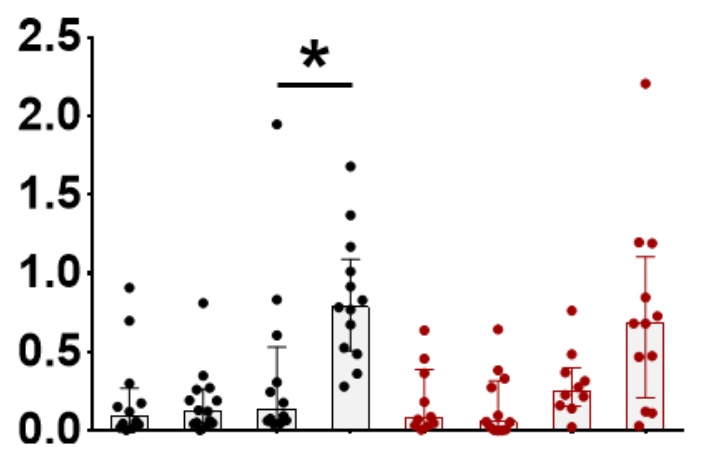

Clostridium

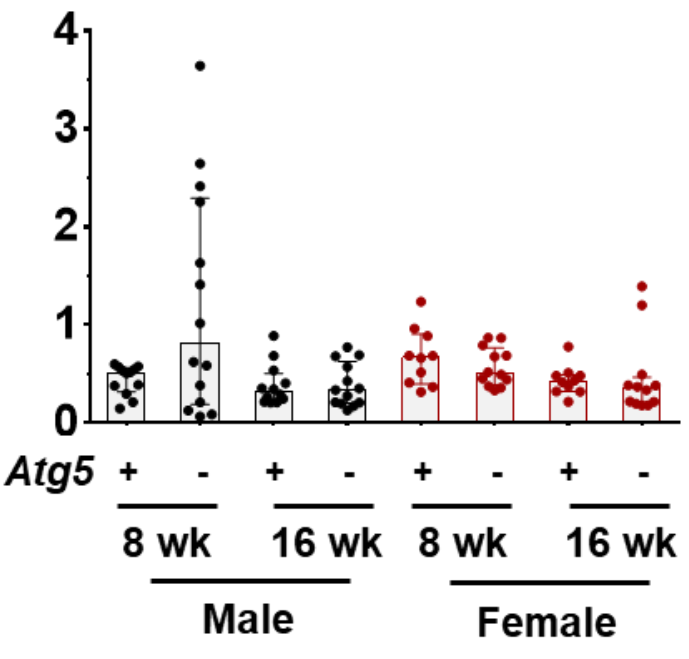

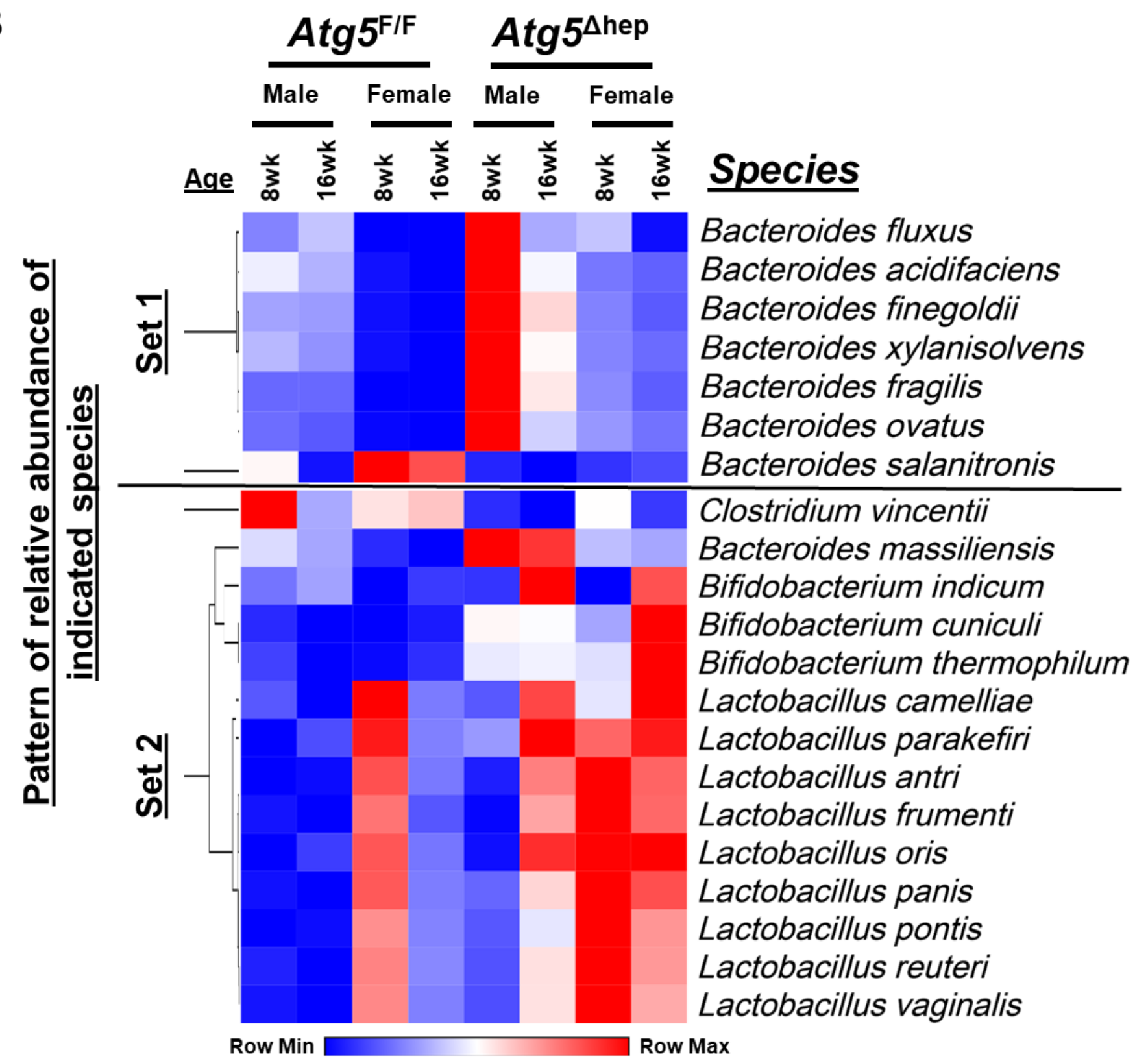


Fig. 3

C

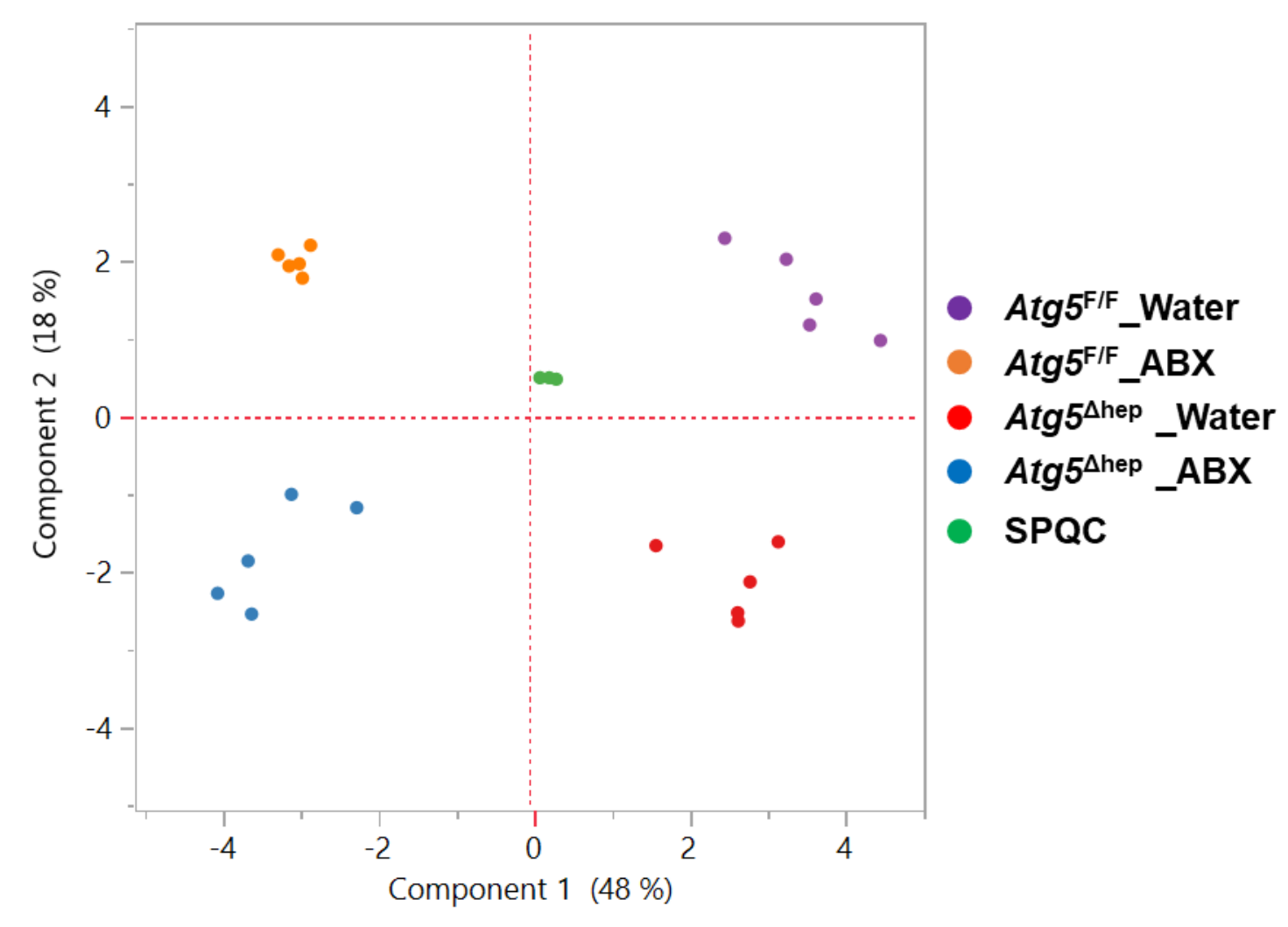

D

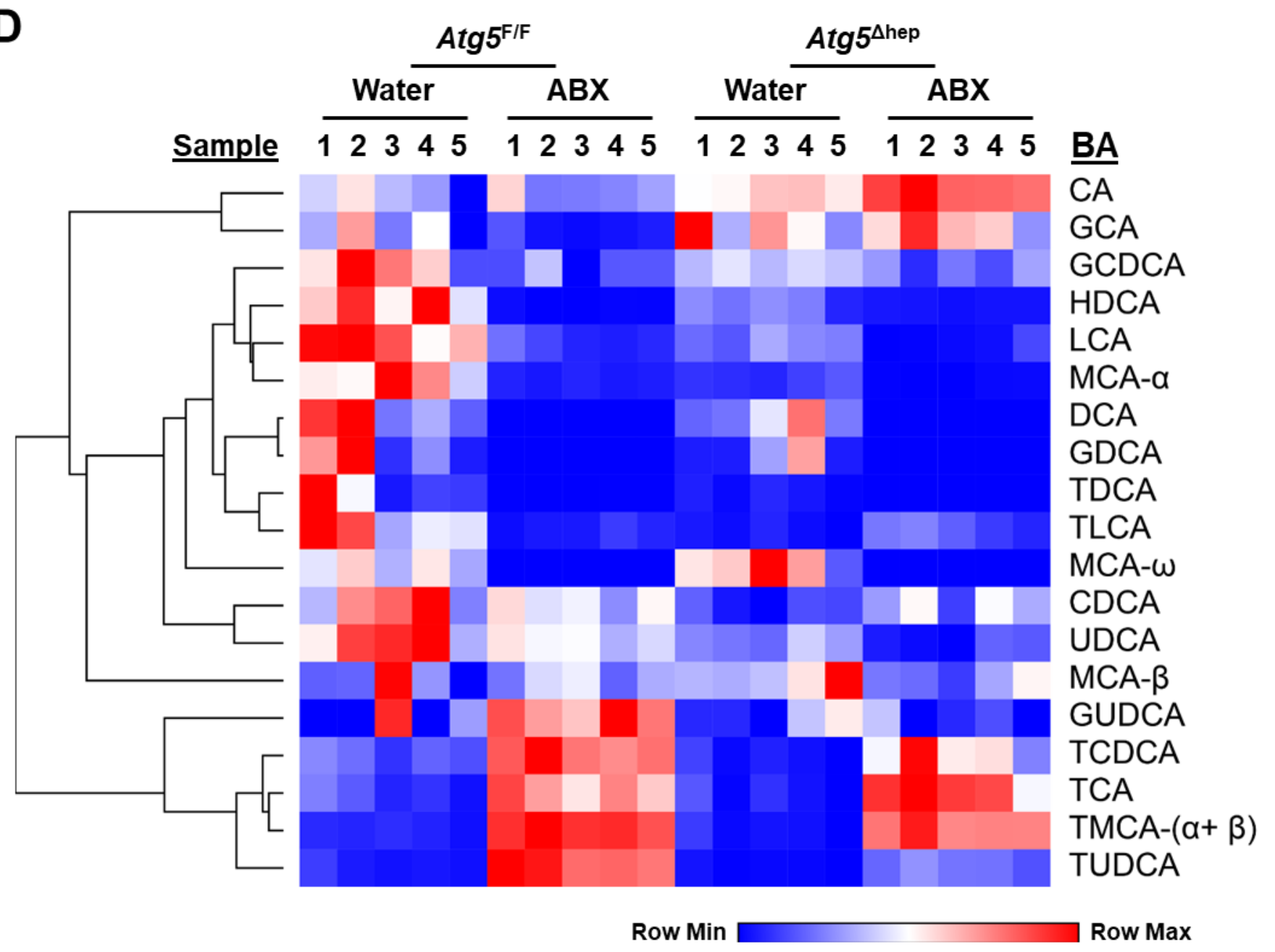


E

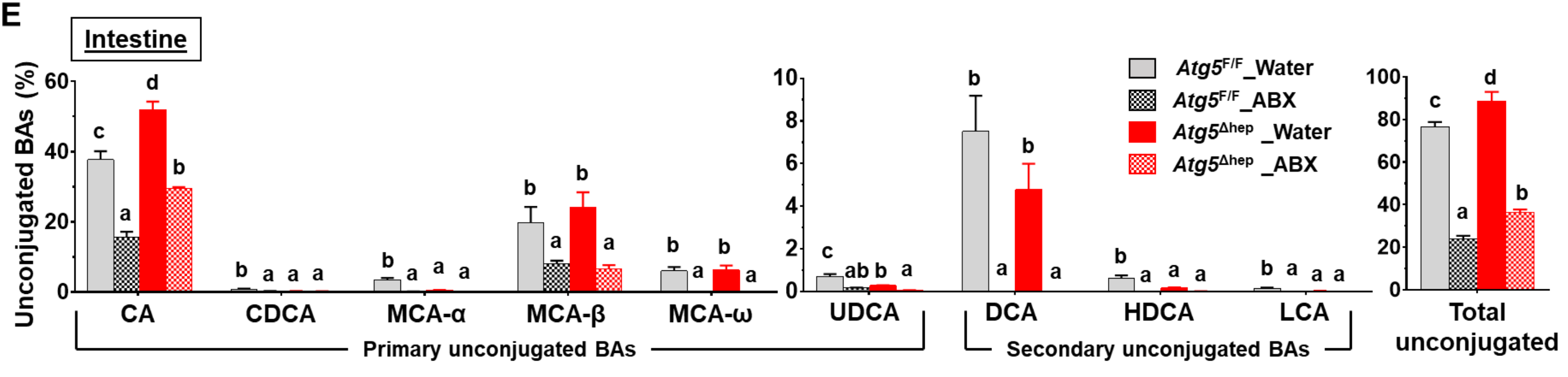

F

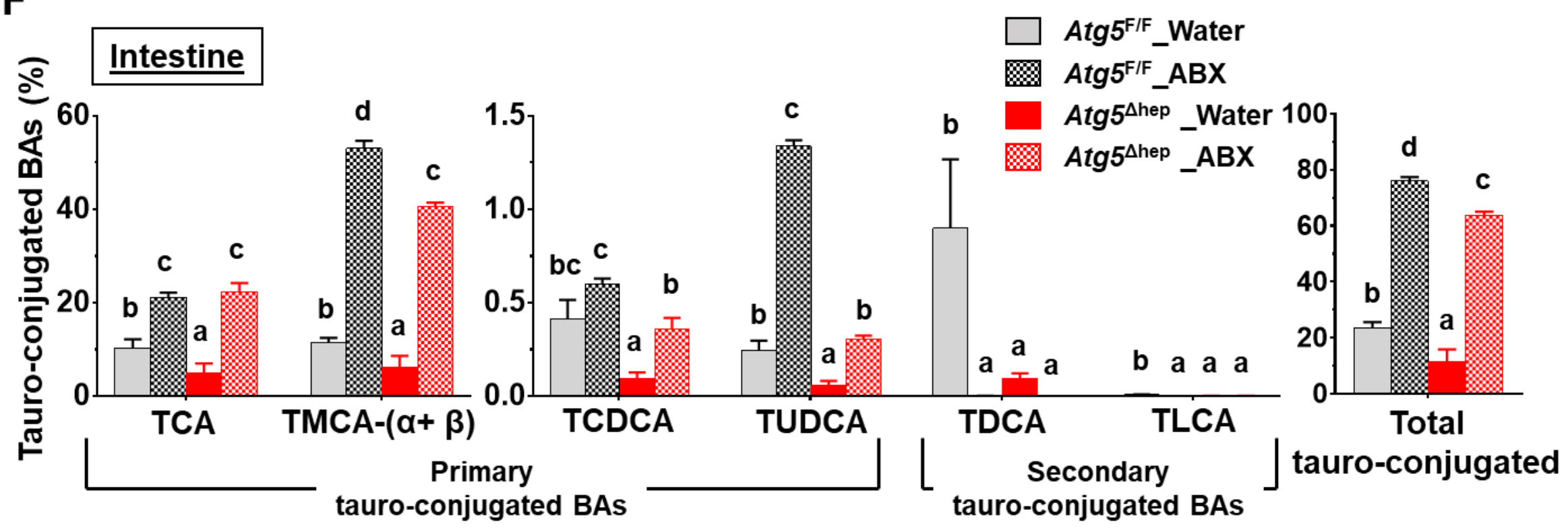




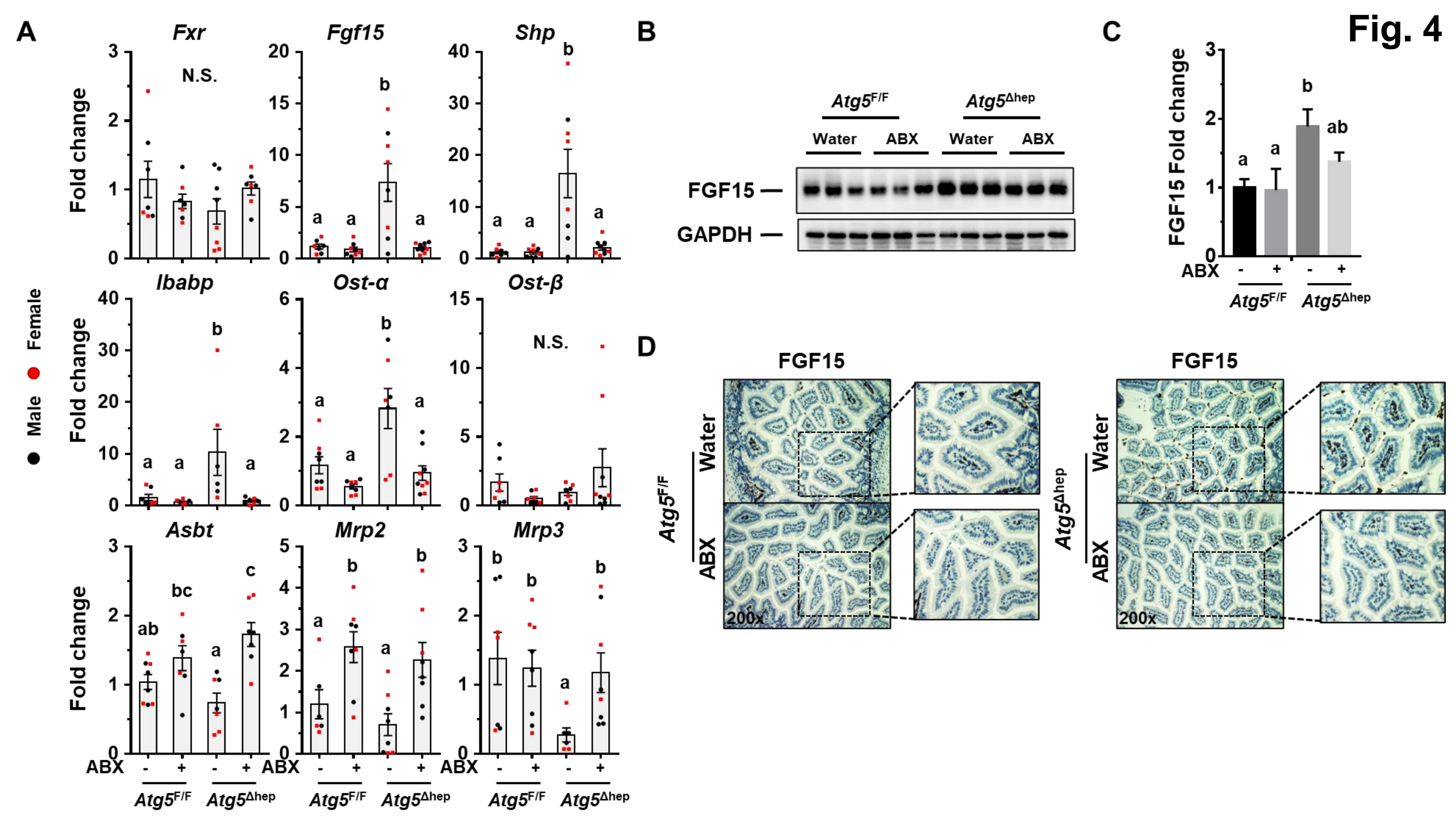


Fig. 4

E

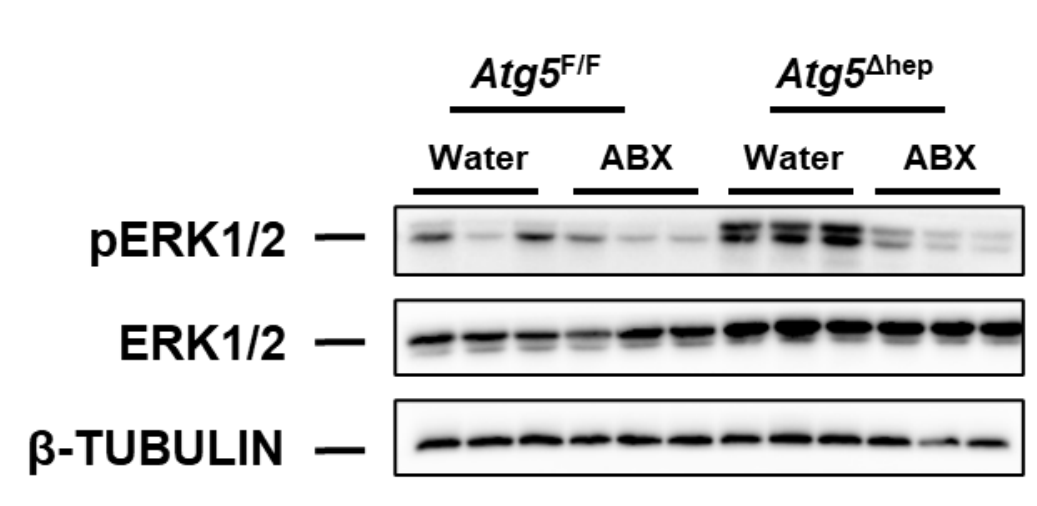

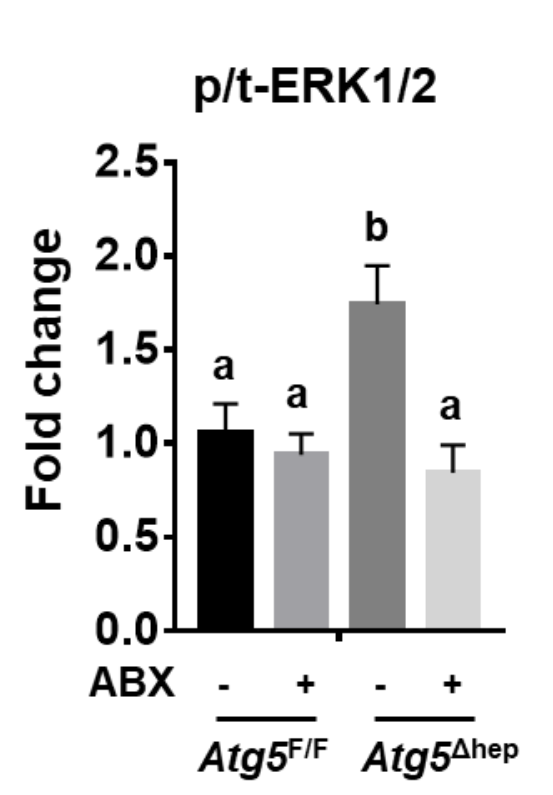

F

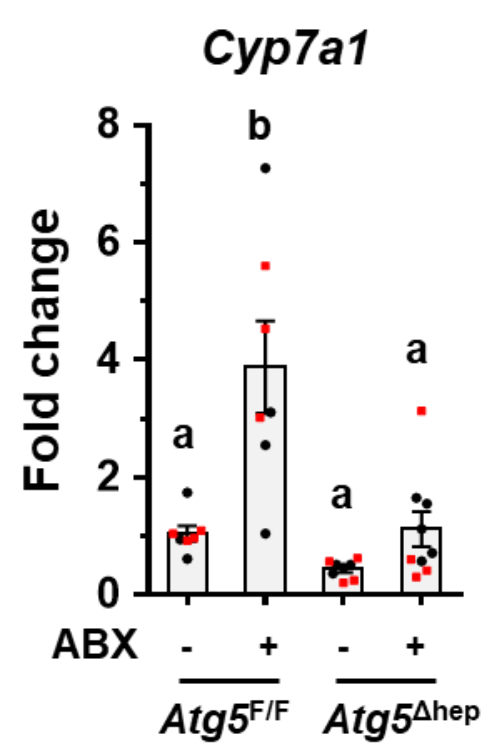


A

B

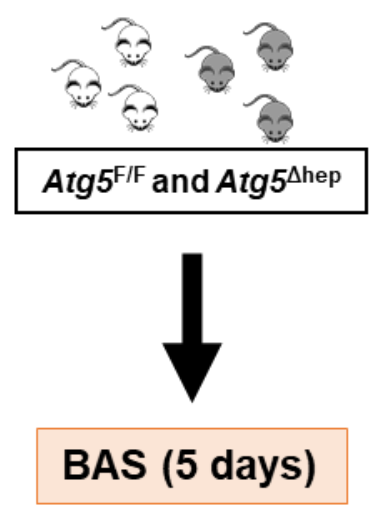

Cholestyramine resin (2 g/kg, twice a day) by gavage or water as control

\section{Male Female}
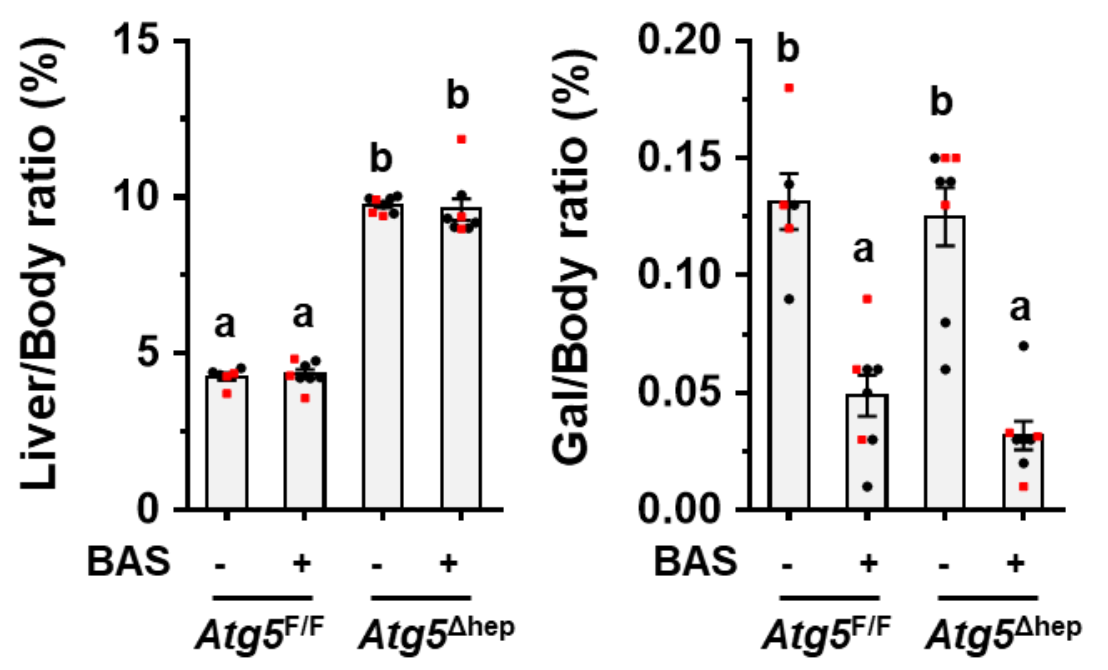

Enterohepatic TBA
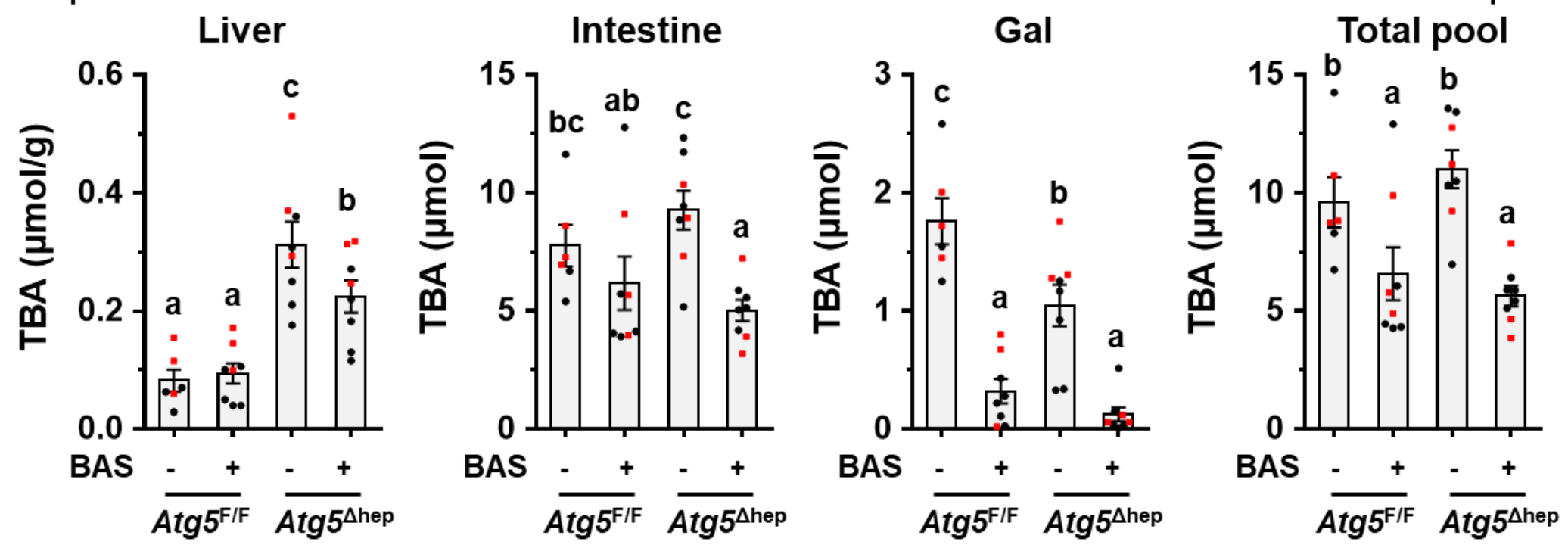

D
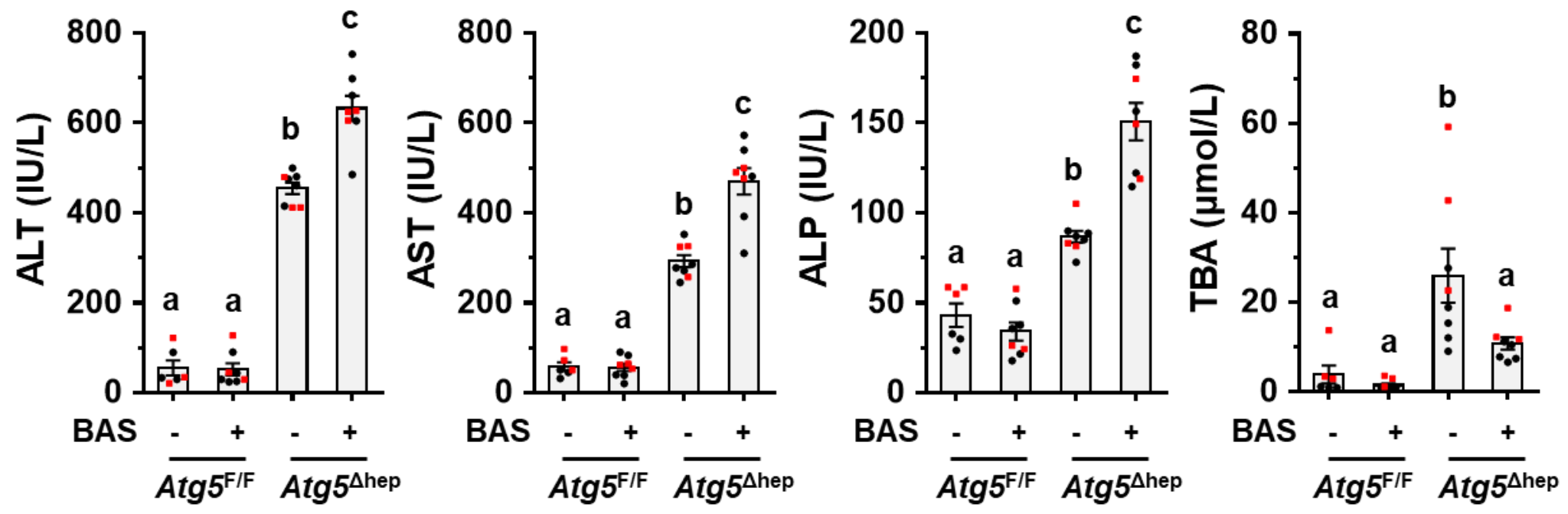
Fig. 5
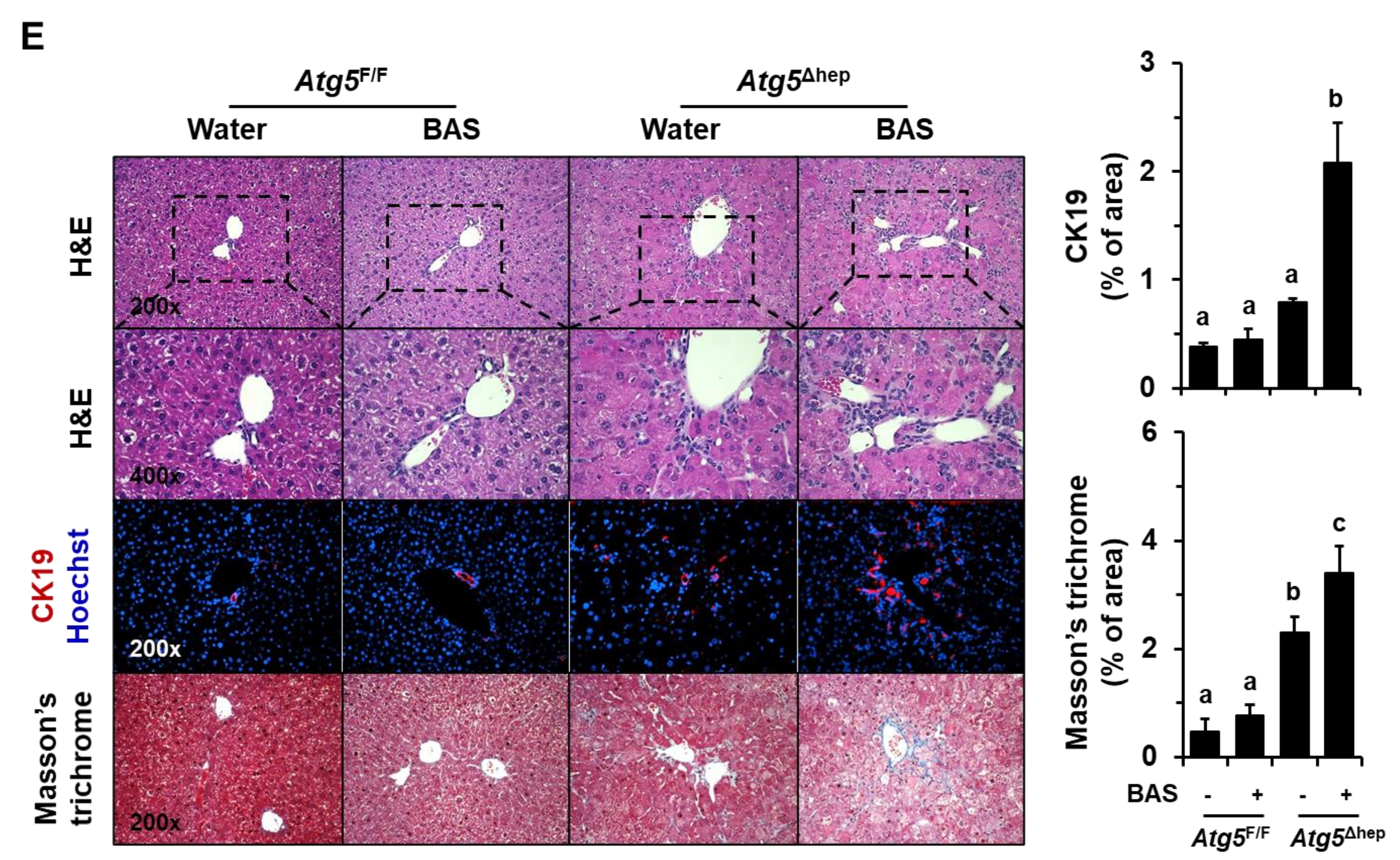
F

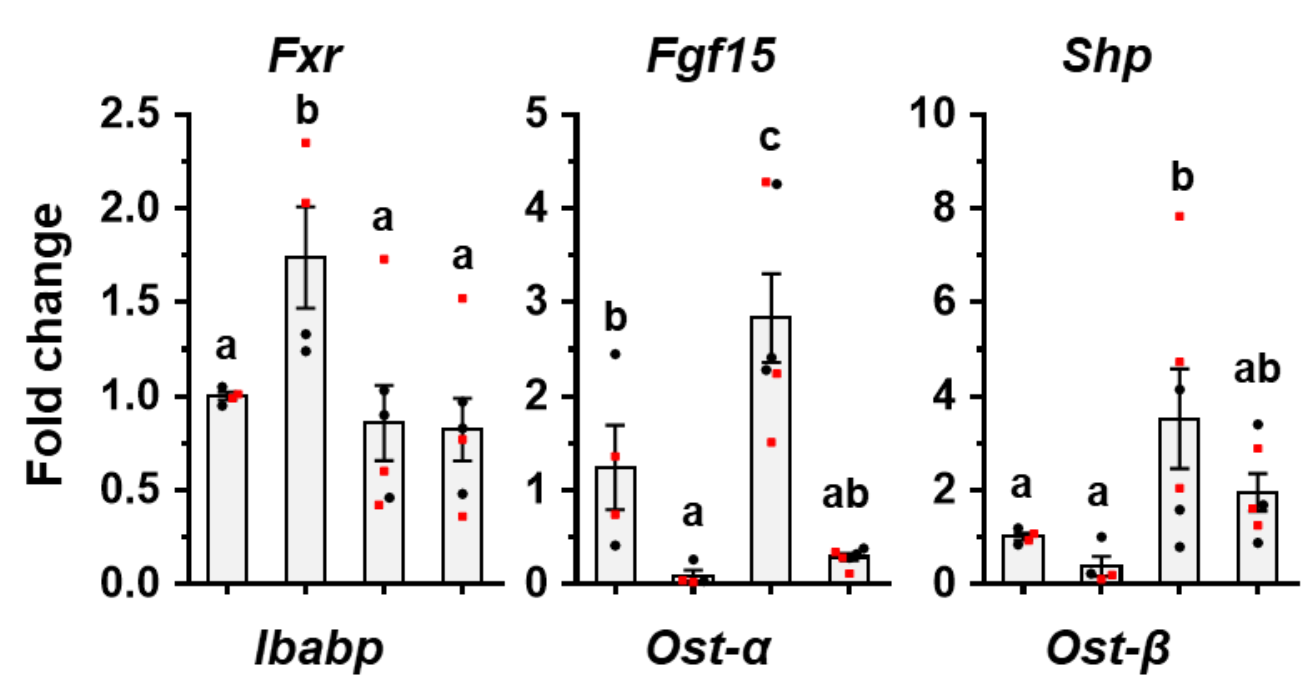

- Male

- Female

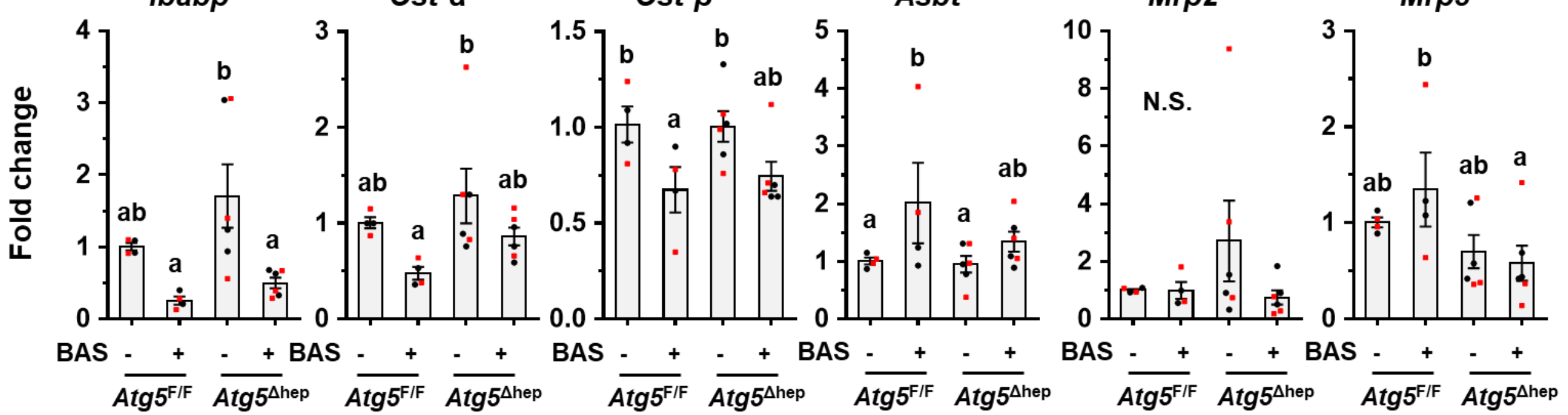


G
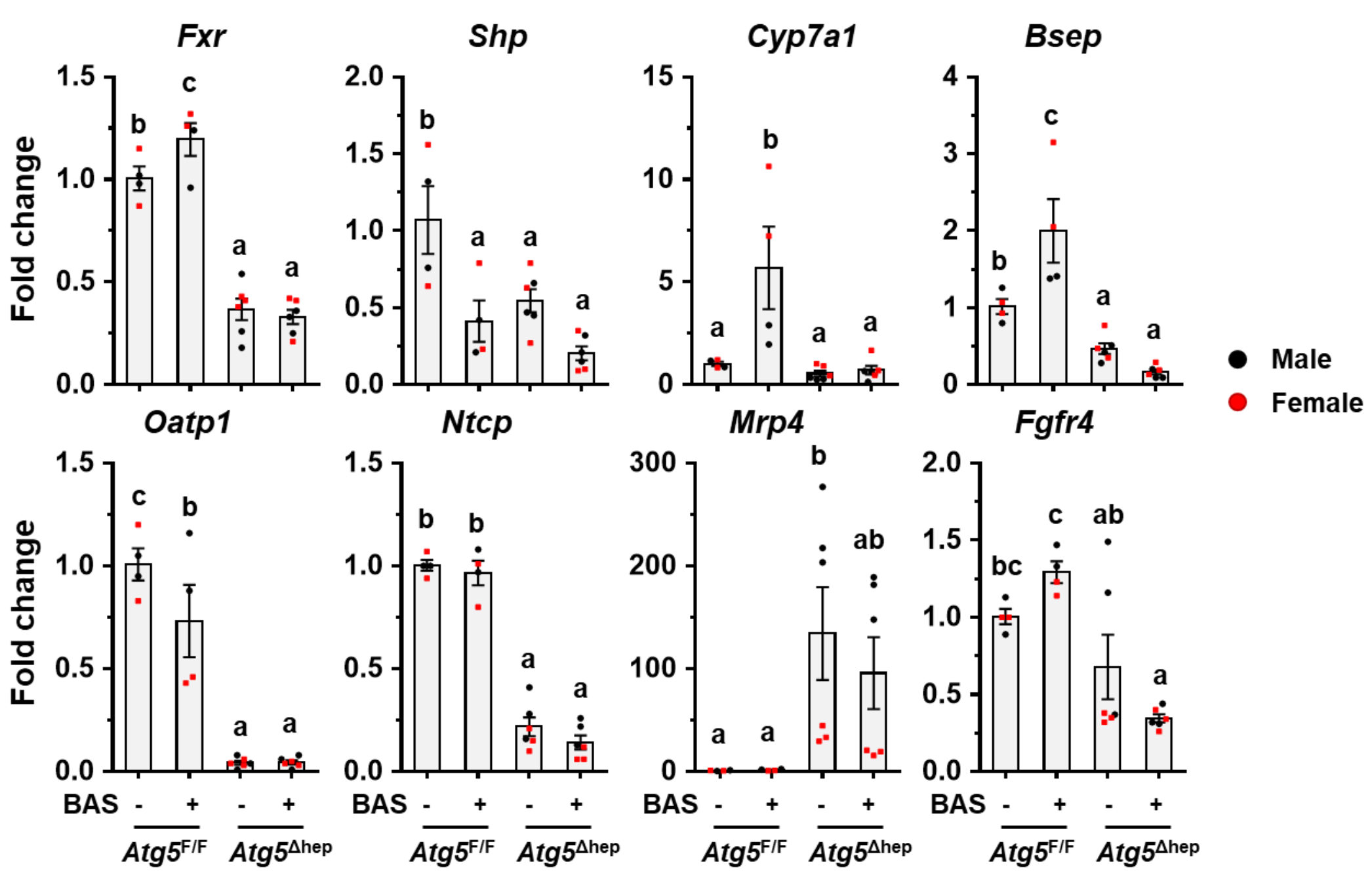
A

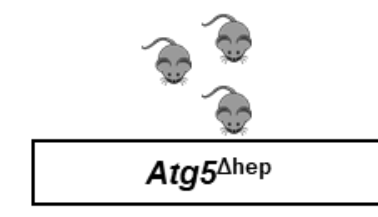

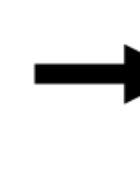

\section{AAV-GFP or AAV-FGF15}

AAV-FGF15 (3×1011 vector genomes per mouse, i.v.), mice injected with same amount of AAV-GFP as control.

B
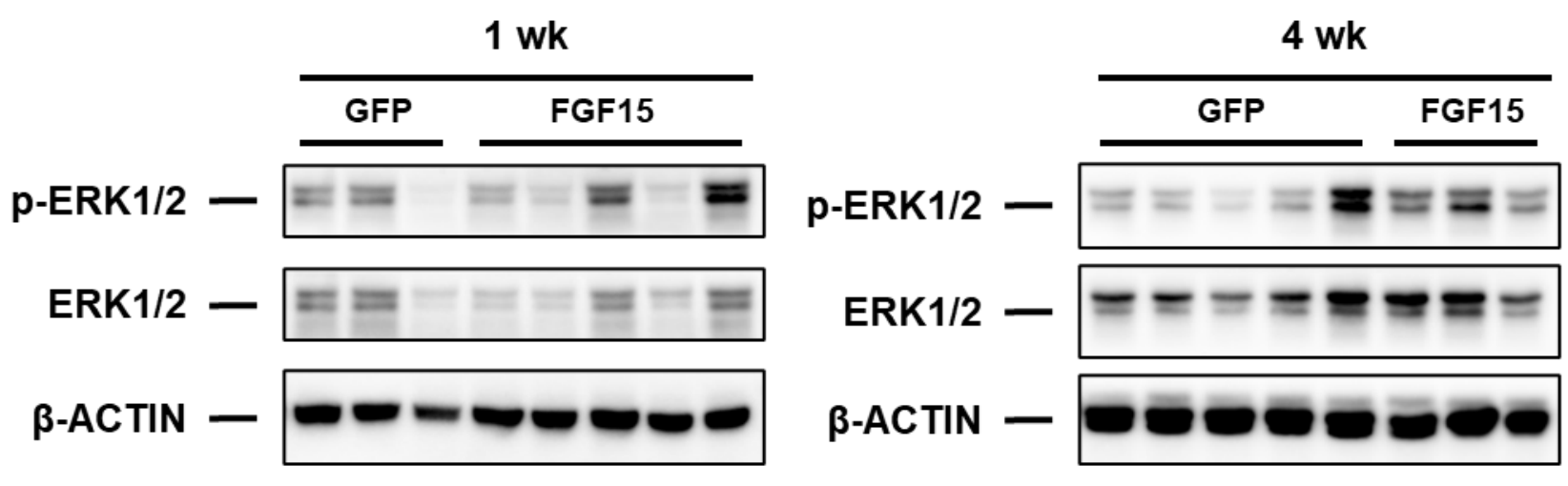

1 or 4 weeks later

Analysis

p/t-ERK1/2

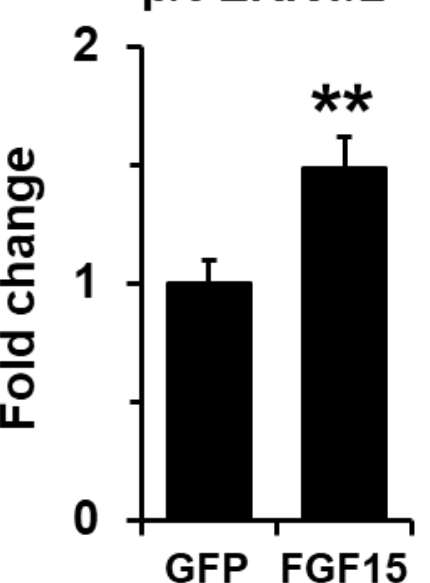

C

Fig. 6
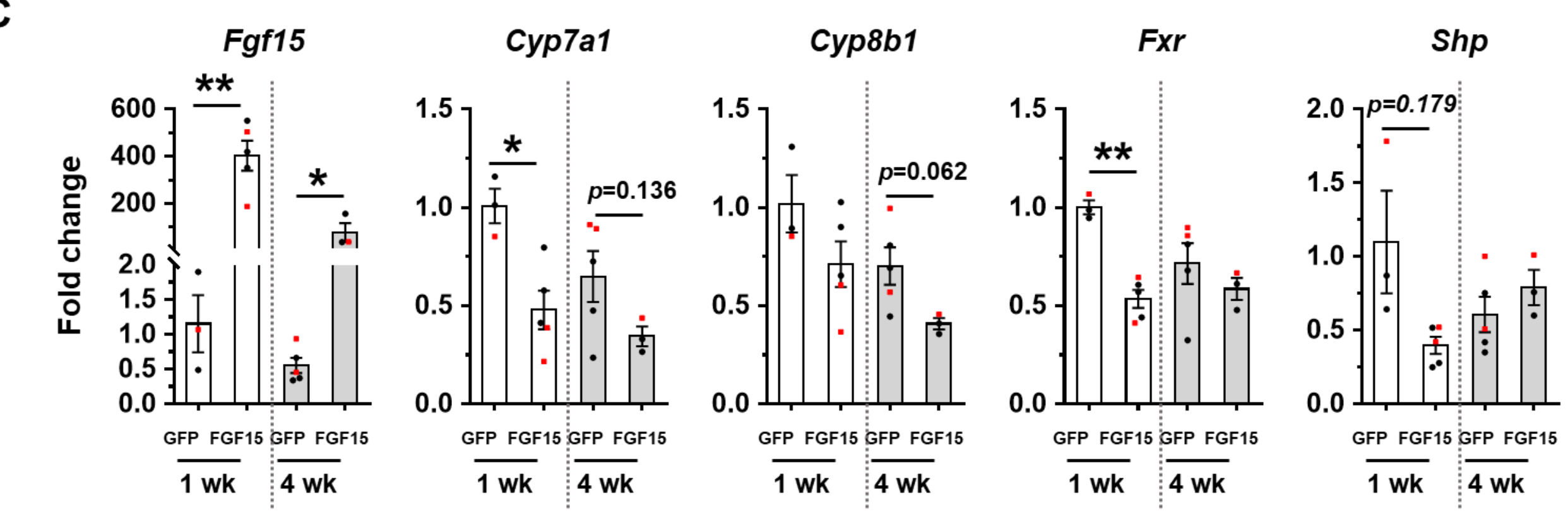

- Male Female Bsep

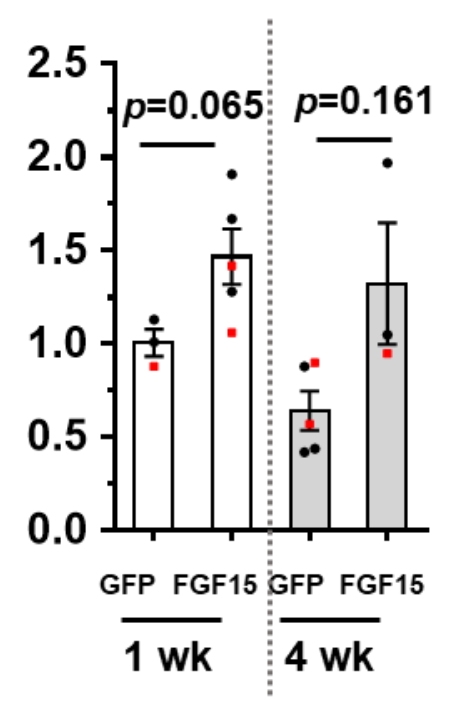


D

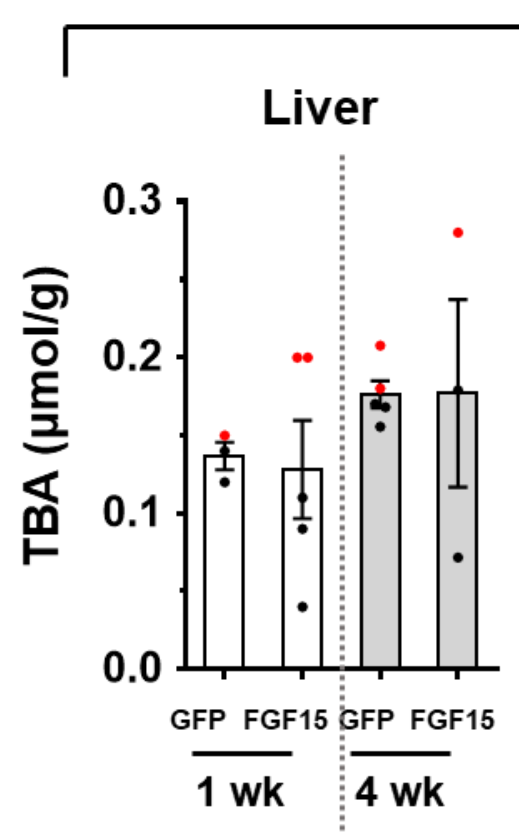

E

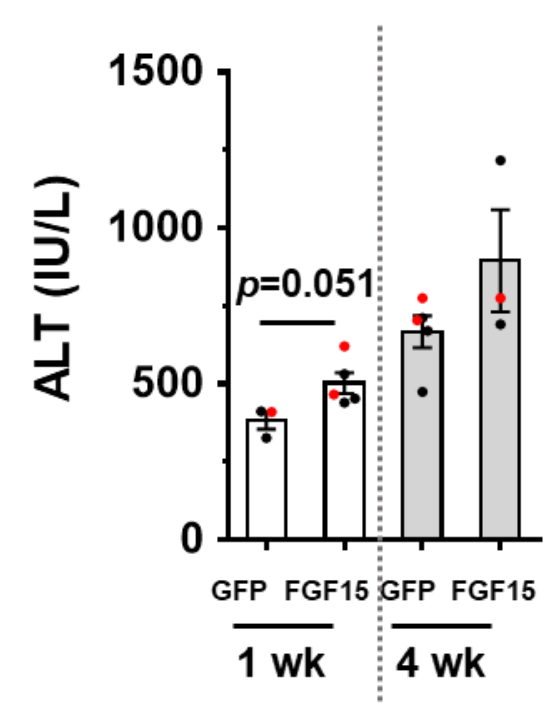

Enterohepatic TBA Intestine
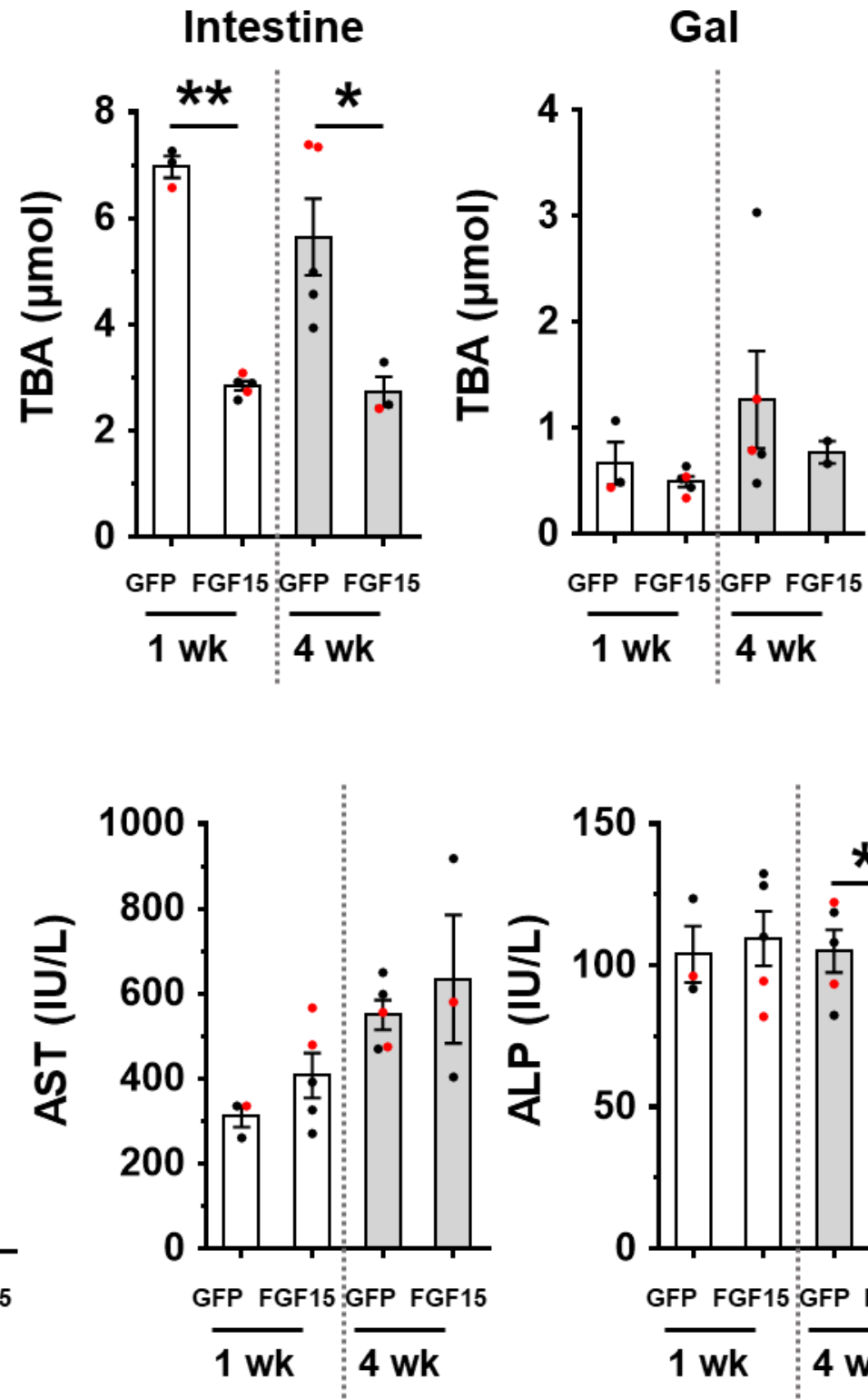

Total pool

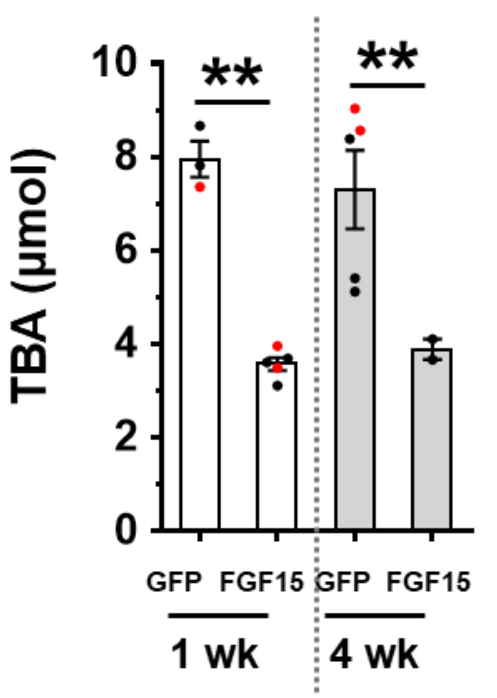

- Male - Female
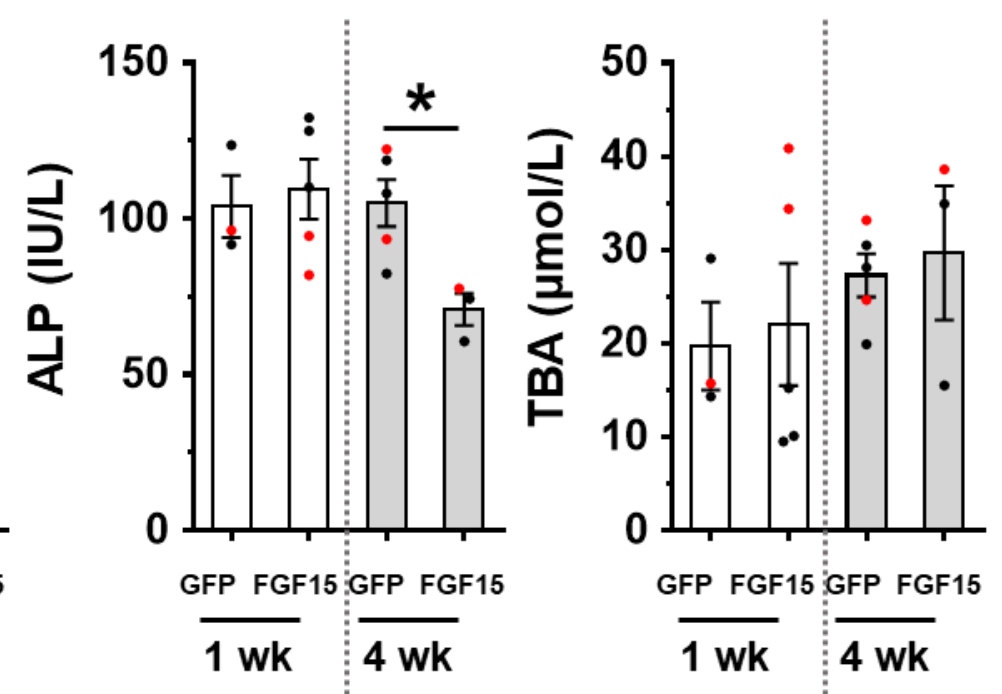

- Male Female

Feces

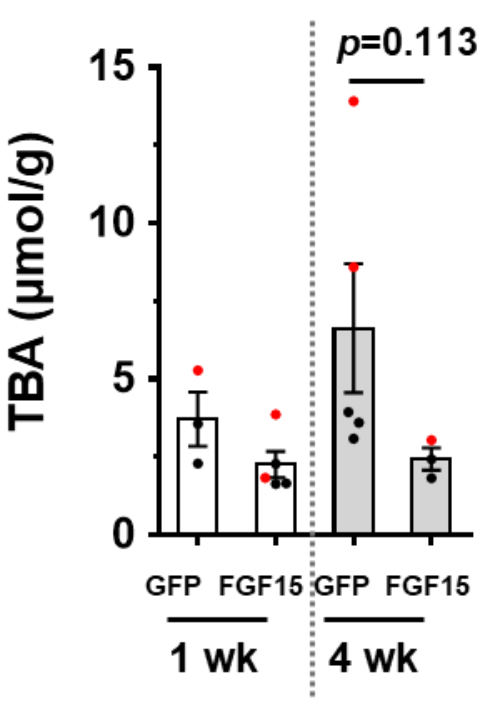


Fig. 6
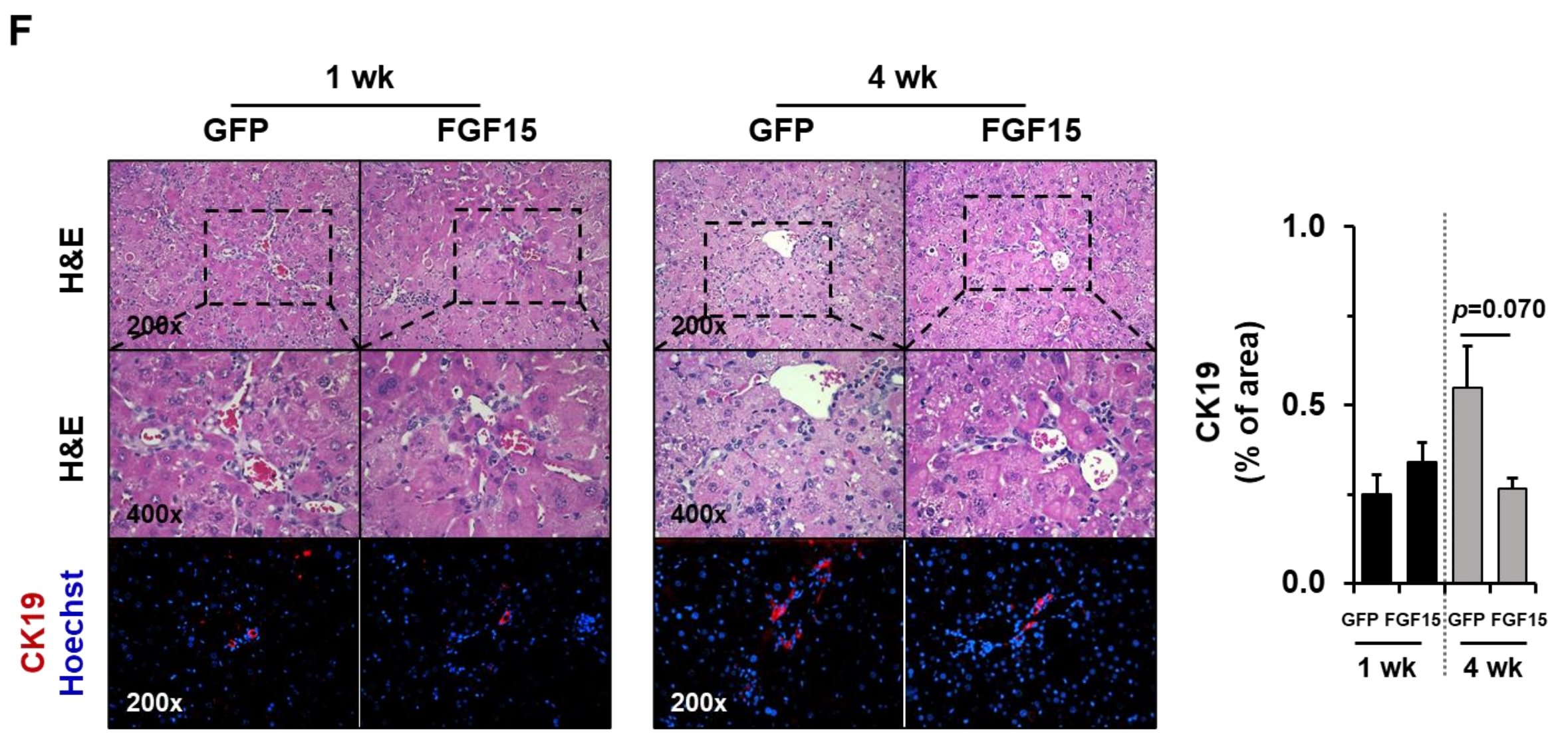


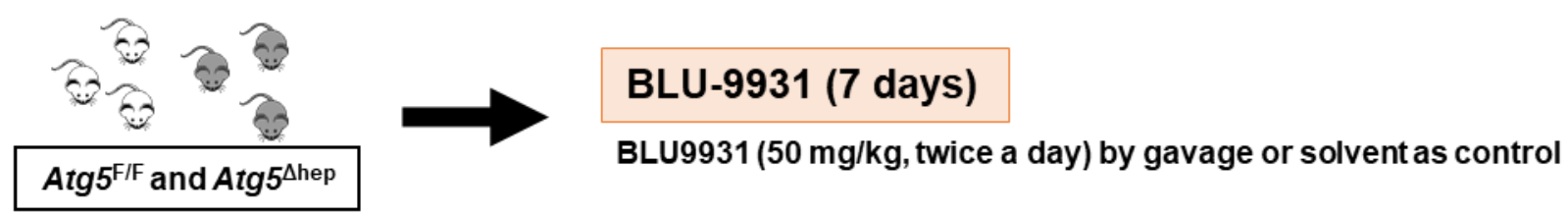

Fig. 7
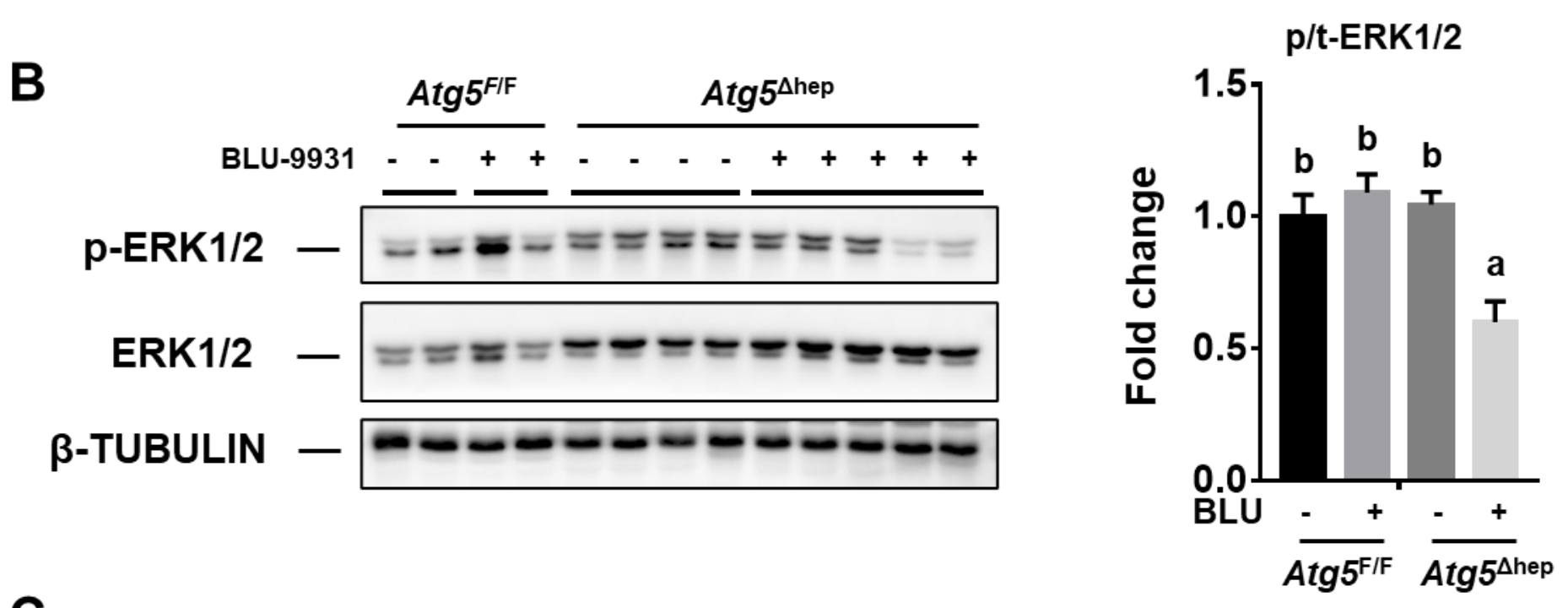

C

- Male - Female

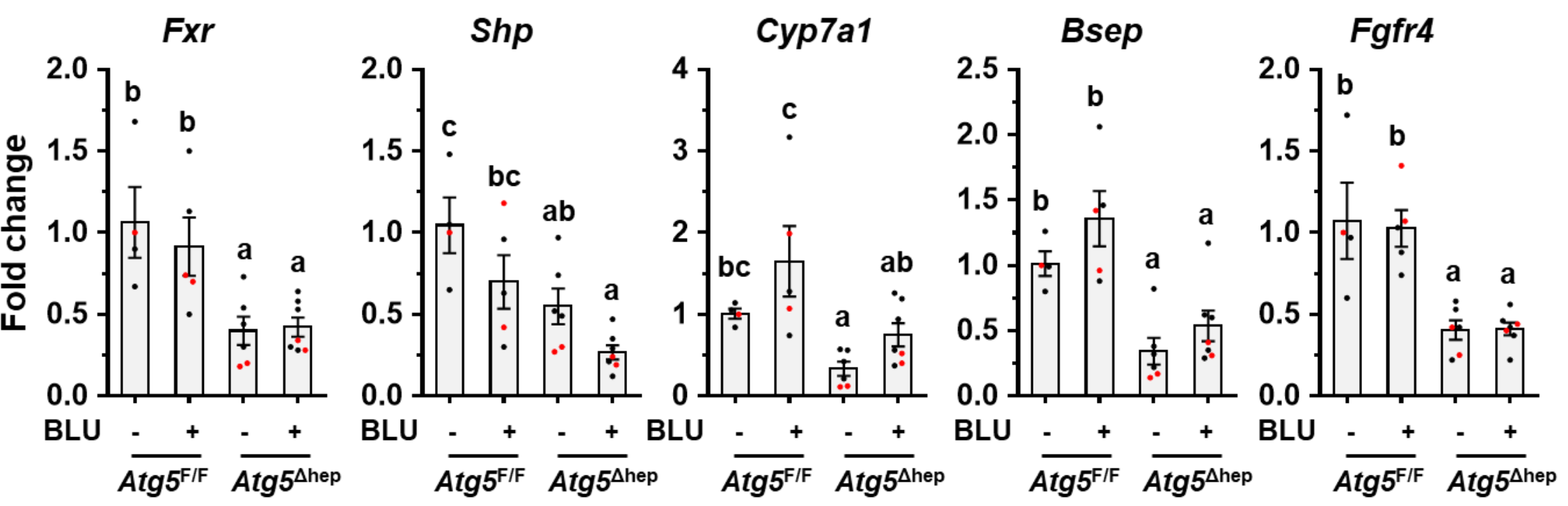


D

Enterohepatic TBA

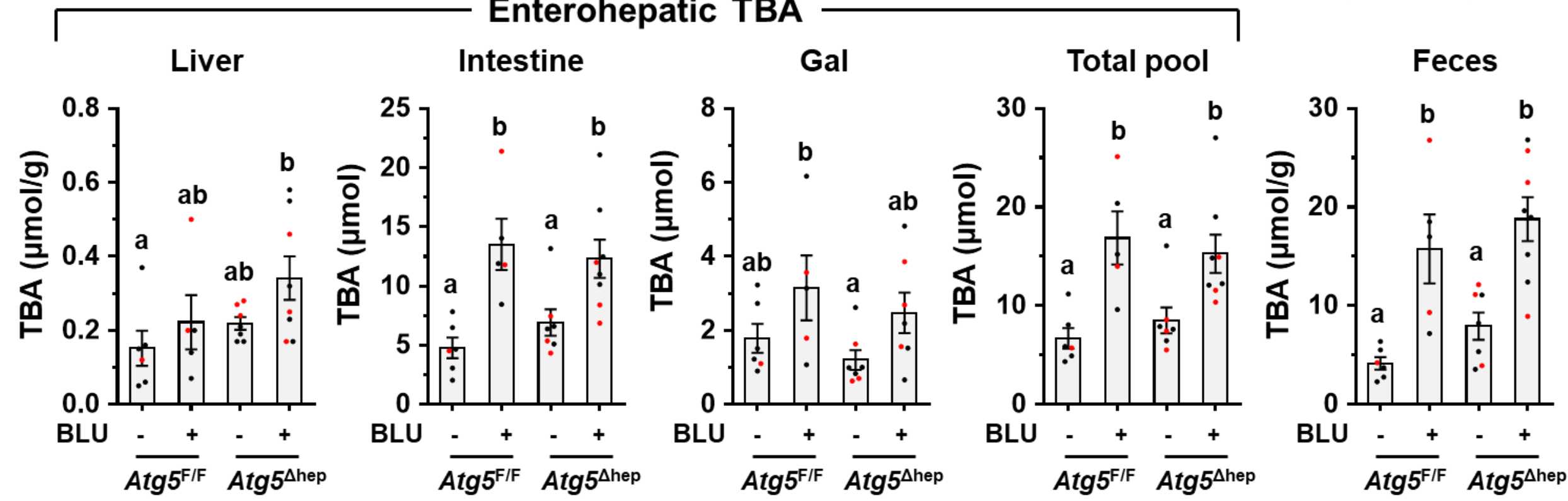

E

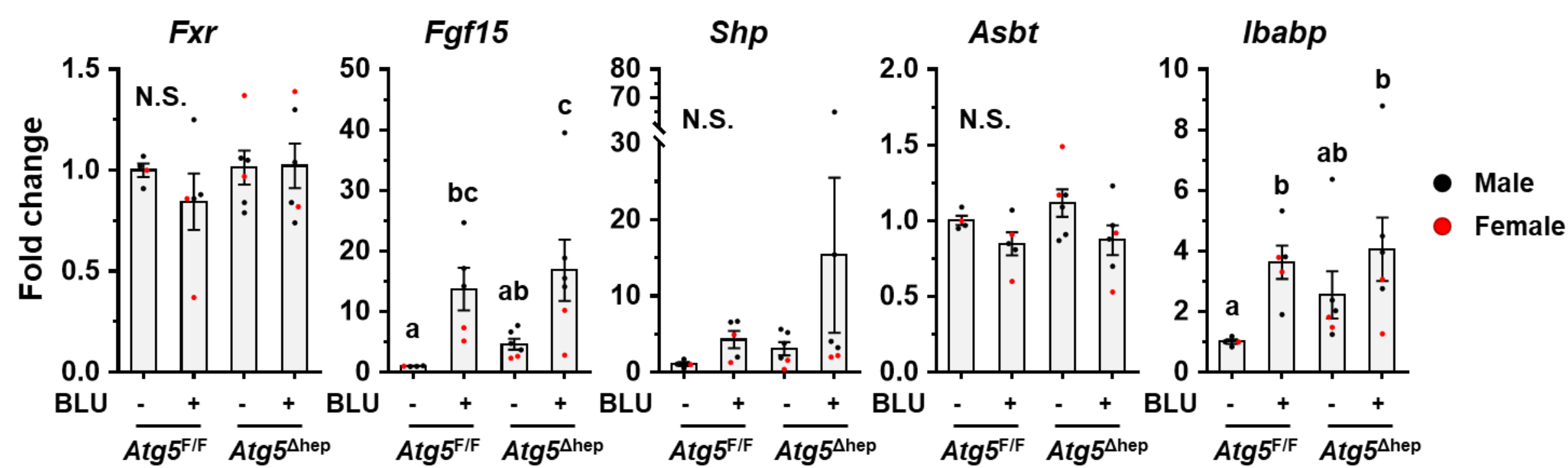


Fig. 7

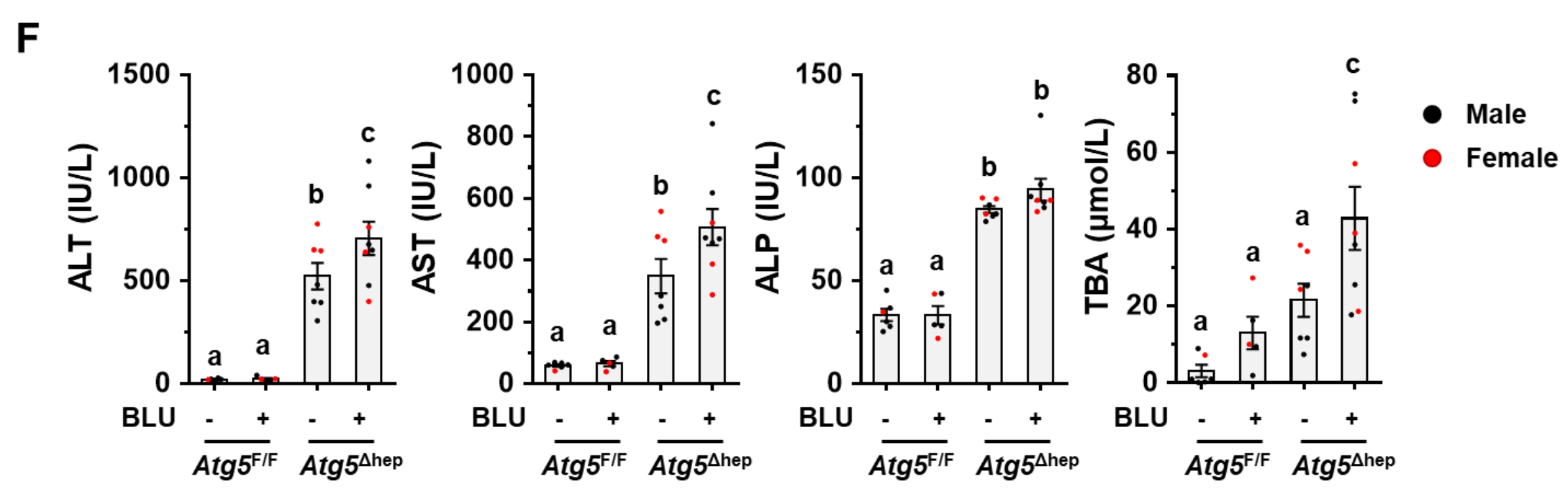


Fig. 7
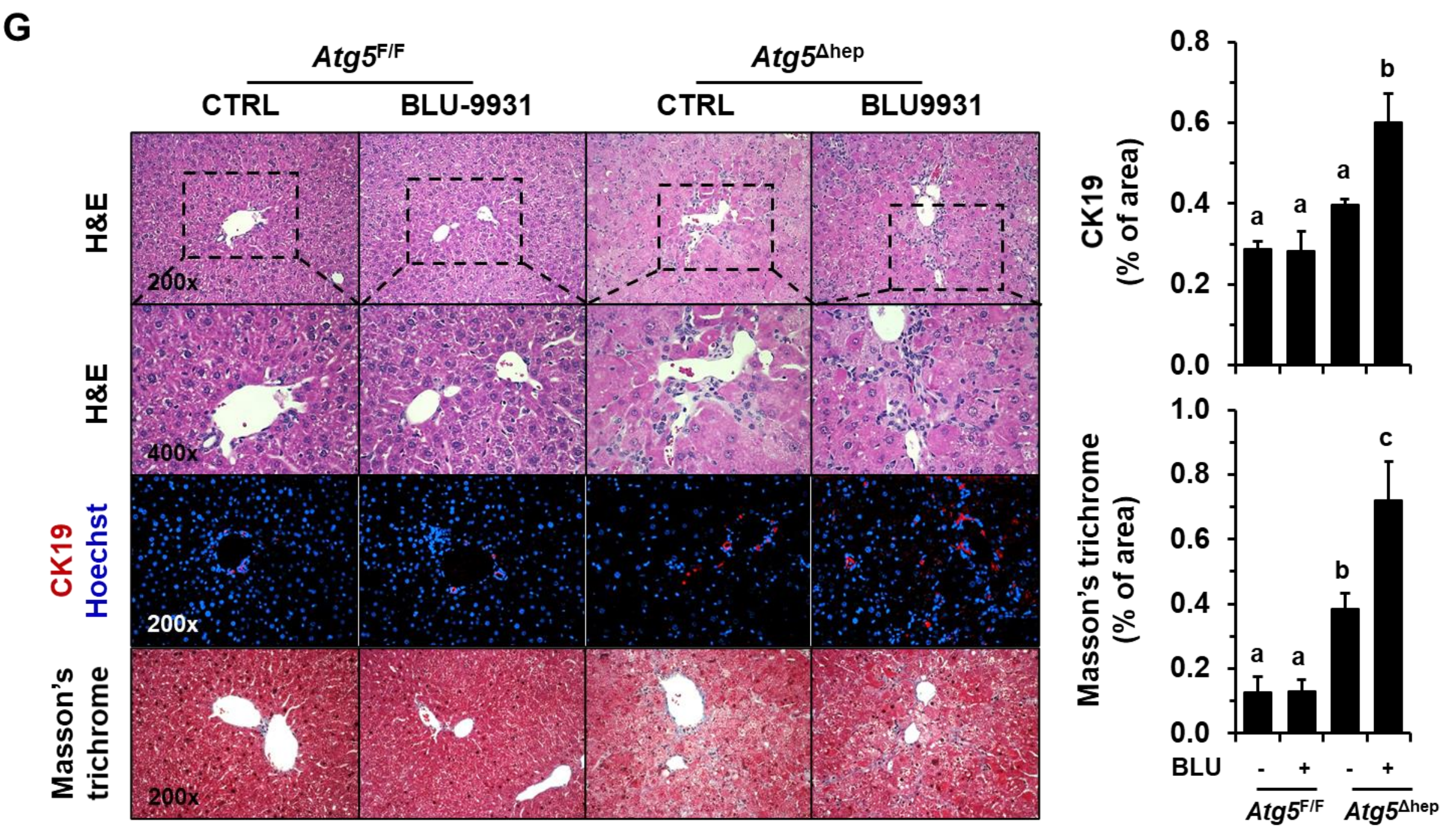
Fig. 8

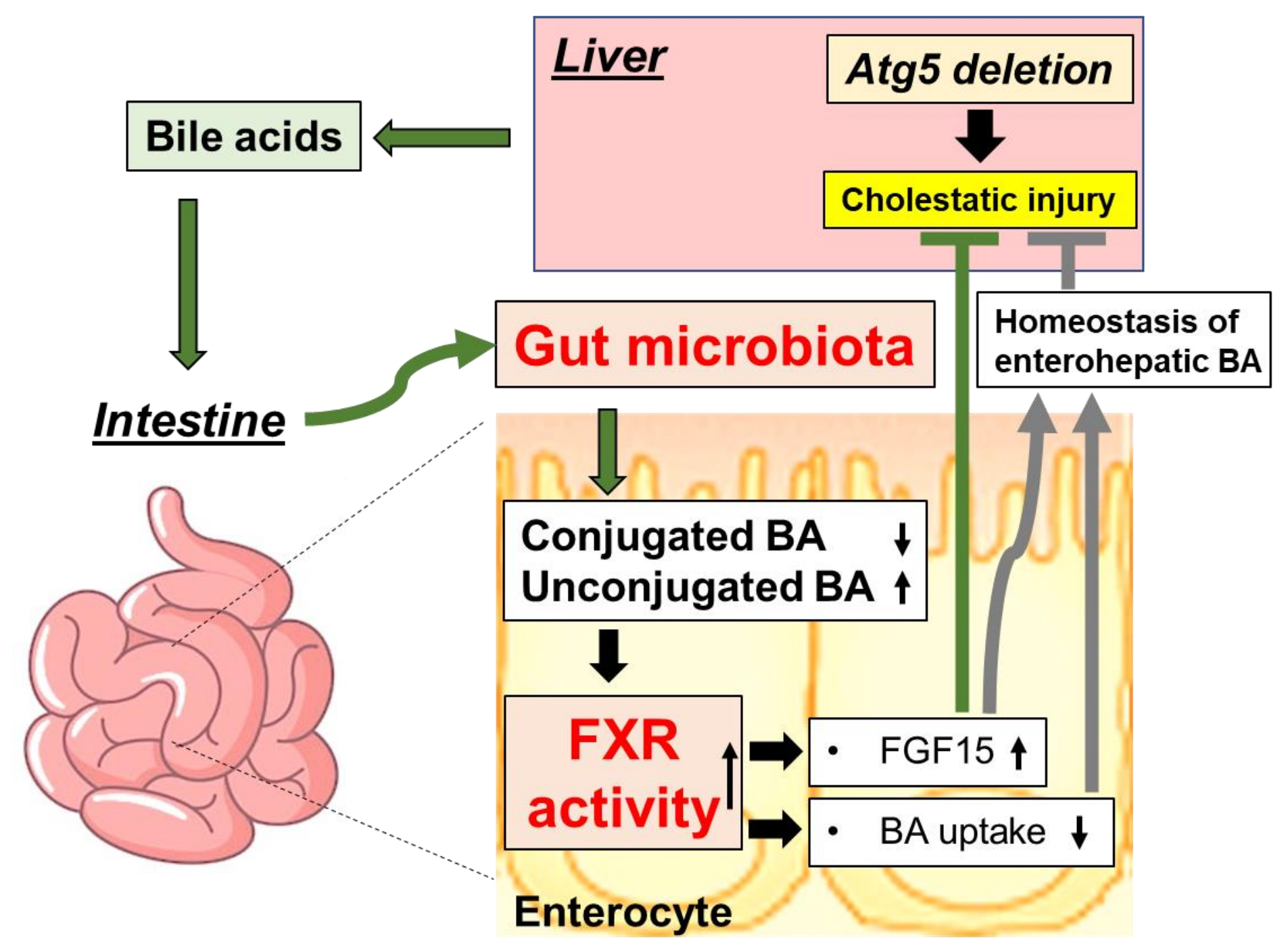

